The FASEB Journal express article 10.1096/fj.01-0528fje. Published online December 14, 2001.

\title{
The role of $\mathrm{CC}$ chemokine receptor 5 (CCR5) and RANTES/CCL5 during chronic fungal asthma in mice ${ }^{1}$
}

Jane M. Schuh*,†, Kate Blease ${ }^{*, \dagger}$, and Cory M. Hogaboam*

*Department of Pathology, University of Michigan Medical School, Ann Arbor, MI.

${ }^{\dagger}$ Both authors contributed equally to this manuscript.

Corresponding author: Cory M. Hogaboam, Department of Pathology, University of Michigan Medical School, Room 5214, Med Sci I, 1301 Catherine Road, Ann Arbor, MI, 48109-0602. E-mail: hogaboam@med.umich.edu

\section{ABSTRACT}

In the present study, we explored the role of $\mathrm{CC}$ chemokine receptor 5 (CCR5) in a murine model of chronic fungal asthma induced by an intrapulmonary challenge with Aspergillus fumigatus conidia (or spores). Airway hyperresponsiveness was significantly lower in $A$. fumigatus-sensitized mice lacking CCR5 (CCR5-/-) compared with similarly sensitized wildtype (CCR5+/+) control mice at days 2, 21, 30, and 40 after the conidia challenge. CCR5-/- mice exhibited significantly less peribronchial T-cell and eosinophil accumulation and airwayremodeling features, such as goblet cell hyperplasia and peribronchial fibrosis, compared with CCR5+/+ mice at these times after conidia. However, both groups of mice exhibited similar allergic airway disease at day 12 after the conidia challenge. In CCR5-/- mice at day 12, the allergic airway disease was associated with airway hyperresponsiveness, peribronchial allergic inflammation, and goblet cell hyperplasia. Immunoneutralization of RANTES/CCL5 in sensitized CCR5+/+ and CCR5-/- mice for 12 days after the conidia challenge significantly reduced the peribronchial inflammation and airway hyperresponsiveness in comparison with control wild-type and knockout mice at this time. These data demonstrate that functional CCR5 and RANTES/CCL5 are required for the persistence of chronic fungal asthma in mice.

Key words: Aspergillus fumigatus $\bullet$ eosinophil • fibrosis • airway hyperreactivity

The CC chemokine receptor CCR5 is expressed in some immune cells, including macrophages and T-cells, and this receptor has a major role in the chemotaxis and activation of the cells that express it $(1,2)$. The major ligand for CCR5 is regulated on Tcell activation, normal T-cell expressed and secreted (RANTES/CCL5), but this receptor also

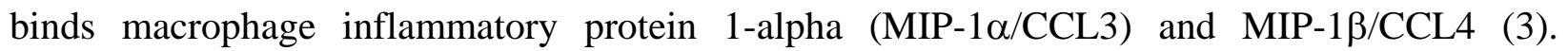
Individuals who are homozygous for a 32-nucleotide deletion (delta 32) within the CCR5 (CCR5 432 ) gene largely remain uninfected despite extensive exposure to HIV-1 (4), whereas heterozygous individuals exhibit limited protection against HIV-associated disease progression (5). More recently, the presence of CCR $5 \Delta 32$ was associated with a reduced risk of developing 
severe rheumatoid arthritis (6) and asthma (7), although subsequent studies question the relationship between CCR5 $\Delta 32$ and asthma $(8,9)$. Originally, CCR5 was characterized as a surface marker of human T-cells producing Th1 cytokines (10), but CCR5 expression is not essential for differentiation of human Th1 cells (11). Other data has shown that distinctions between chemokine receptor expression on Th1 and Th2 cells may be absent in vivo $(3,12)$.

There is considerable evidence that lung (13-17) and plasma (18) levels of RANTES/CCL5 are elevated in allergic asthmatic patients. Furthermore, elevations in RANTES/CCL5 persuasively correlate with eosinophil and T-cell recruitment into the airways of allergen-challenged asthmatics (15-17, 19-23). In addition, single-nucleotide polymorphisms in the proximal RANTES/CCL5 promoter have been identified $(24,25)$, and one polymorphism in particular has been associated with an increased susceptibility to both atopy and asthma (26). Although it has been shown that RANTES/CCL5 interaction with CCR5 promotes the selective migration of Th1 cells in vitro (27-29), experimental studies using acute models of Th2-mediated allergic airway disease have shown that RANTES/CCL5 is the major eosinophil (30) and T-cell chemoattractant $(31,32)$ that consequently modulates airway hyperresponsiveness to nonspecific spasmogens such as methacholine (32). The pro-asthmatic and allergic effects of RANTES/CCL5 may be mediated through its other receptors: CCR1, CCR3, and to a lesser extent CCR4 (33-35).

In light of the controversy regarding the role of CCR5 in the development of asthma and allergic airway disease, we investigated the consequences of CCR5 gene deletion in a murine model of chronic fungal asthma. In the present study, the role of RANTES/CCL5 and its receptor, CCR5, were examined in the context of chronic fungal asthma. We have shown previously that the pulmonary response to conidia in A. fumigatus-sensitized mice includes chronic airway hyperresponsiveness, goblet cell hyperplasia, and subepithelial fibrosis (36). In addition, we have observed that chemokine receptors exert prominent effects on the development and maintenance of the asthmatic disease in these mice. For example, A. fumigatus-sensitized mice lacking CCR1 maintain airway hyperresponsiveness but do not exhibit persistent airway remodeling following a conidia challenge (37). Conversely, CCR2-/- mice failed to clear A. fumigatus conidia and as a result developed severe allergic airway disease (38). Fungus-induced allergic airway responses in CCR5-/- mice have not been reported previously, leading us to examine the response of these mice and their wild-type controls $(\mathrm{CCR} 5+/+)$ to an intratracheal challenge of $A$. fumigatus conidia following pulmonary sensitization to soluble antigens of the same fungus.

\section{MATERIALS AND METHODS}

\section{Mice}

CCR5 wild-type (+/+) mice (B6129F2/J) and CCR5 knockout (-/-) mice (B6129F2/J$\mathrm{Cmkbr}^{\mathrm{tm} 1 \mathrm{kuz}}$ ) mice were purchased from Jackson Laboratories (Bar Harbor, ME) or derived from breeding stocks at the University of Michigan (courtesy of Gary Huffnagle). Both groups of mice were maintained under specific pathogen-free conditions in the University Laboratory for Animal Medicine facility at the University of Michigan Medical School. At 5 to 6 wks of age, male and female CCR5-/- and CCR5+/+ mice were sensitized to a commercially available preparation of soluble A. fumigatus antigens as previously described in detail (36). A. fumigatus- 
sensitized CCR5+/+ and CCR5-/- mice then received $5.0 \times 10^{6}$ A. fumigatus conidia suspended in $30 \mu \mathrm{l}$ of PBS tween $80(0.1 \%$, vol/vol) via the intratracheal route (36).

\section{Measurement of bronchial hyperresponsiveness}

Bronchial hyperresponsiveness in both groups of mice ( $n=4-7$ mice/group) was assessed by using a Buxco ${ }^{\mathrm{TM}}$ plethysmograph (Buxco, Troy, NY) (36) at days 2, 12, 21, 30, and 40 after the conidia challenge. Briefly, sodium pentobarbital (Butler Co., Columbus, OH; $0.04 \mathrm{mg} / \mathrm{g}$ of mouse body weight) was injected into mice before their intubation and ventilation with a Harvard pump ventilator (Harvard Apparatus, Reno, NV) (36). After a baseline period of 5 min, the mouse received $1 \mu \mathrm{g}$ of methacholine by tail-vein injection. Airway hyperresponsiveness was calculated via the division of the transpulmonary pressure by the change in inspiratory volume (36). Immediately following the assessment of airway hyperresponsiveness, the mouse was killed, a bronchoalveolar lavage (BAL) was performed by using $1 \mathrm{ml}$ of normal saline, and 500 $\mu \mathrm{l}$ aliquot of blood was removed from each mouse for analysis. Finally, whole lungs were dissected from each mouse and snap-frozen in liquid $\mathrm{N}_{2}$ or prepared for histological analysis (see below).

\section{Immunoneutralization of RANTES/CCL5}

We conducted immunoneutralization of RANTES/CCL5 by i.p. injection of $20 \mu \mathrm{g}$ of purified anti-murine RANTES antibody at two-day intervals between day 0 and 12 after the conidia challenge: the biological half-life of the antibody is approximately $48 \mathrm{~h}$. The amount of antibody was more than sufficient to neutralize systemic endogenous RANTES/CCL5. Goat anti-murine RANTES/CCL5 was prepared on contract with Lampire Biological Laboratories (Pipersville, PA) by using a 14-amino acid carboxyl-terminal peptide of murine RANTES/CCL5 kindly provided by B. Daugherty (Merck, Whitehouse Station, NJ). We determined antiserum titer to be $>1: 1 \times 10^{7}$ by direct ELISA and confirmed neutralization by inhibition of RANTES/CCL5elicited eosinophil chemotaxis. The antibody does not cross-react with other assayed murine recombinant cytokines and chemokines. As a control, preimmune, normal goat, purified IgG was used. The endotoxin content in anti-RANTES/CCL5 antibody and control IgG was typically below detection level $(<0.05$ EU/ml Pyrogent; BioWhittaker, Walkersville, MD). AHR was assessed at day 12 after conidia.

\section{Morphometric analysis of leukocyte accumulation in BAL samples}

We centrifuged the BAL samples at 2,000 rpm for 5 min and removed the supernatants. The pelleted cells were resuspended in $200 \mu \mathrm{l}$ of normal saline and transferred to coded microscope slides via Cytospin (Shandon Scientific, Runcorn, U.K.). Each slide was stained with a WrightGiemsa differential stain, and the average number of each cell type-neutrophil, macrophage, eosinophil, or lymphocyte - was determined after counting a total of 10-20 high-powered fields (hpf; 1,000×) per slide. BAL cell counts are represented as the average number of a specific cell type per hpf. 


\section{ELISA analysis}

Total IgE levels were measured in $1-\mu 1$ aliquots of mouse serum. Murine RANTES/CCL5, C10/CCL6, eotaxin/CCL11, IL-4, and IFN- $\gamma$ were determined in 50- $\mu$ l aliquots of whole lung homogenates using a standardized sandwich ELISA technique (39). Nunc-immuno ELISA plates (MaxiSorp ${ }^{\mathrm{TM}}$ ) were coated with the appropriate polyclonal capture antibody (R\&D Systems, Minneapolis, $\mathrm{MN}$ ) at a dilution of $1-5 \mu \mathrm{g} / \mathrm{ml}$ of coating buffer (in $\mathrm{M}$ : $0.6 \mathrm{NaCl}, 0.26 \mathrm{H}_{3} \mathrm{BO}_{4}$, $0.08 \mathrm{NaOH} ; \mathrm{pH} 9.6)$ overnight at $4 \mathrm{C}$. The unbound capture antibody was washed away, and each plate was blocked with $2 \%$ BSA-PBS for $1 \mathrm{~h}$ at $37 \mathrm{C}$. Each ELISA plate was then washed three times with PBS tween $20(0.05 \%$; vol/vol), and $50 \mu \mathrm{l}$ of undiluted or diluted $(1: 10)$ whole lung homogenate was added to duplicate wells and incubated for $1 \mathrm{~h}$ at $37^{\circ} \mathrm{C}$. Following the incubation period, the ELISA plates were washed thoroughly and the appropriate biotinylated polyclonal detection antibody $(3.5 \mu \mathrm{g} / \mathrm{ml})$ was added. After washing the plates 45 min later, we added streptavidin-peroxidase (Bio-Rad Laboratories, Richmond, CA) to each well for $30 \mathrm{~min}$, after which we thoroughly washed the plates again. A chromagen substrate solution (Bio-Rad Laboratories) was added, and optical readings at $492 \mathrm{~nm}$ were obtained by using an ELISA plate scanner. Recombinant murine chemokines, cytokines, or IgE were used to generate the standard curves from which the concentrations present in the samples were derived. The limit of ELISA detection for each cytokine was consistently above $50 \mathrm{pg} / \mathrm{ml}$. Each ELISA was screened to ensure the specificity of each antibody used. The cytokine and immunoglobulin levels in each sample were normalized to total protein levels using the Bradford assay.

\section{Soluble collagen analysis}

We have observed previously that peribronchial fibrosis peaks at day 30 after a conidia challenge in A. fumigatus-sensitized mice (36). In the present study, soluble forms of collagen were measured in whole lung homogenates from both groups of mice using the Sircol ${ }^{\mathrm{TM}}$ Collagen Assay (Biocolor Ltd., Belfast, Ireland). This assay was developed from the Sirius Red-based histochemical procedure. The collagen levels in each sample were normalized to total protein levels by using the Bradford assay.

\section{Whole lung histological analysis}

Whole lungs from A. fumigatus-sensitized CCR5+/+ and CCR5-/- mice, before and after $A$. fumigatus conidia challenge, were dissected from the thoracic cavity, fully inflated with $4 \%$ paraformaldehyde, and placed in fresh paraformaldehyde for $24 \mathrm{~h}$. Routine histological techniques were used to paraffin-embed the entire lung, and 5- $\mu \mathrm{m}$ sections of whole lung were stained with either hematoxylin and eosin (H\&E) or periodic acid Schiff (PAS). We examined inflammatory infiltrates and structural alterations around blood vessels and airways by using light microscopy at a magnification of $200 \times$.

\section{Statistical analysis}

All results are expressed as mean \pm SE. We performed statistical analysis at each time point before and after the conidia challenge by using the unpaired Student's $t$-test to calculate the twotailed $P$ value; $P<0.05$ was considered statistically significant. 


\section{RESULTS}

\section{Total IgE levels are greater in A. fumigatus-sensitized CCR5-/- mice before and at day $\mathbf{4 0}$ after an intratracheal challenge with conidia}

Previous studies have shown that the T-cell-dependent humoral response to a specific antigen challenge is enhanced significantly in CCR5-/- mice compared with CCR5+/+ mice (40). In the present study, serum levels of total IgE were increased significantly in CCR5-/- mice before and at day 40 after the conidia challenge compared with CCR5+/+ mice at the same time points (Fig. 1). The greatest levels of serum IgE were detected in both groups of mice at day 12 after conidia, but serum IgE levels were not significantly different between the two groups of mice at this time, nor at days 2 or 21 after the conidia challenge (Fig. 1). The presence of total IgE in serum samples confirmed that CCR5-/- mice developed allergic responsiveness to soluble A. fumigatus antigens, but serum IgE levels were similar between the two groups at most times after the conidia challenge.

Transient changes in airway hyperresponsiveness in A. fumigatus-sensitized CCR5+/+ and CCR5-/- mice following a challenge with conidia

Airway hyperresponsiveness following a methacholine challenge is a persistent feature of chronic fungal asthma in mice (36). The sensitization of CCR5-/- and CCR5+/+ mice to $A$. fumigatus was not associated with a marked increase in airway resistance following methacholine administration (data not shown), but airway hyperresponsiveness to methacholine was observed in both groups after the introduction of conidia (Fig. 2). Whereas CCR5+/+ mice exhibited 6- to 15-fold increases in airway resistance above the baseline level (represented by a dashed line on Fig. 2) at all times after the conidia challenge, CCR5-/- exhibited pronounced airway hyperresponsiveness only at day 12 after the conidia challenge (Fig. 2). At days 2, 21, 30, and 40, methacholine-induced airway resistance was significantly lower in CCR5-/- mice when compared with CCR5+/+ mice at the same time after the conidia challenge. Taken together, these data showed that, in contrast to wild-type mice sensitized with A. fumigatus, the development of airway hyperresponsiveness was delayed and transitory in A. fumigatussensitized CCR5-/- mice after a live conidia challenge.

\section{Temporal changes in RANTES/CCL5 during chronic fungal asthma}

Whole lung RANTES/CCL5 levels in both groups of mice during the course of chronic fungal asthma is summarized in Figure 3. It was apparent that the pattern of expression for this CC chemokine differed markedly between the groups. Immediately before the introduction of conidia (time =0), RANTES/CCL5 levels were approximately 6-fold higher in whole lung samples from CCR5-/- mice compared with CCR5+/+ mice. At days 2 and 12 after the conidia challenge, both groups of mice exhibited similar levels of RANTES/CCL5. However, at all later times after the conidia challenge, whole lung samples from CCR5-/- mice contained significantly greater levels of RANTES/CCL5 compared with the appropriate wild-type control group (Fig. 3). In contrast, whole lung levels of other putative CCR5 ligands such as MIP-1 $\alpha /$ CCL3 and 
MIP-1 $\beta / C C L 4$ did not differ between the two groups of mice before, or at any time after, the conidia challenge (data not shown).

\section{Temporal changes in eosinophil chemoattractants C10/CCL6 and Eotaxin/CCL11 during chronic fungal asthma}

Specific ELISA analysis of whole lung levels of eosinophil chemoattractants C10/CCL6 (Fig. $\underline{4 \mathrm{~A}}$ ) and eotaxin/CCL11 (Fig. 4B) revealed major time-dependent changes in the levels of these chemokines during the course of chronic fungal asthma in CCR5+/+ and CCR5-/- mice. Before conidia, whole lung levels of C10/CCL6 and eotaxin/CCL11 were significantly lower in CCR5/- mice compared with the wild-type controls. C10/CCL6 levels remained significantly lower in whole lung samples from CCR5-/- mice at days 2 and 12 after conidia compared with levels of this chemokine in similar samples from CCR5+/+ mice (Fig 4A). At day 21 after conidia, the opposite profile was observed in that whole lung levels of both eosinophil chemoattractants were increased significantly in CCR5-/- mice compared with CCR5+/+ mice. However, at later time points (days 30 and 40), no significant differences in whole lung levels of C10/CCL6 and eotaxin/CCL11 were observed between CCR5-/- and CCR5+/+ mice (Fig. 4A, B). These data highlighted CCR5-/- mice's marked deficit in eosinophil chemoattractants before and at early times after the conidia challenge.

\section{Transient peribronchial inflammation in A. fumigatus-sensitized CCR5-/- mice following a challenge with conidia}

Figure 5 summarizes the temporal changes in peribronchial inflammation present in $A$. fumigatus-sensitized mice CCR5+/+ and CCR5-/- mice at various times after a conidia challenge. The histological picture immediately before the conidia challenge suggested that little peribronchial inflammation was present in either CCR5+/+ mice (Fig. 5A) or CCR5-/- mice (Fig. $\underline{5 B}$ ). At day 2 after conidia, both groups of mice exhibited pronounced perivascular inflammation; peribronchial inflammation was apparent in CCR5+/+ mice (Fig. 5C), but not in CCR5-/- mice (Fig. 5D). At day 12 after conidia, peribronchial inflammation was prominent in both groups of mice (Fig. 5E, F). However, it was interesting to note that eosinophils were almost completely lacking around the airways of CCR5-/- mice at this time. Histological analysis at day 21 after the conidia challenge revealed that peribronchial inflammation and peribronchial fibrosis (pink spindle-shaped cells) were prominent in CCR5+/+ mice (Fig. 5G), but neither of these features of allergic airway disease were observed in CCR5-/- mice (Fig. 5H). At day 40 after conidia, peribronchial inflammation had by and large resolved in both groups (Fig. 5I, J). Thus, the histological features of chronic fungal asthma were apparent only in CCR5-/- mice at day 12 after the conidia challenge.

\section{Temporal changes in leukocyte numbers in bronchoalveolar lavage from A. fumigatus-sensitized CCR5-/- and CCR5+/+ mice following a conidia challenge}

Changes in leukocyte numbers in the BAL appear to reflect that intensity of the airway inflammatory response during chronic fungal asthma (36). Consistent with our previous findings (36), the neutrophil was the prominent leukocyte, comprising more than $50 \%$ of the cells present in the BAL of CCR5+/+ and CCR5-/- mice, at day 2 after the conidia challenge (Fig. 6). Also at 
this time, lymphocytes and eosinophils were significantly less abundant in BAL samples from CCR5-/- mice compared with CCR5+/+ mice. At day 12 after conidia, macrophages were observed in significantly higher numbers in CCR5-/- mice compared with CCR5+/+ mice (Fig. 6). Lymphocyte, eosinophil, and neutrophil numbers were equivalent in both groups of mice at this time after the conidia challenge. However, lymphocyte and eosinophil numbers were again significantly lower at day 21 after conidia in CCR5-/- mice compared with corresponding BAL samples from CCR5+/+ mice (ig. 6). At day 40 after conidia, lymphocytes remained significantly reduced in CCR5-/- mice. The number of eosinophils in both groups was so low that it is doubtful if this cell type had physiologic impact at this time point (ig. 6). Thus, the migration of major leukocyte subsets into the airways appeared to be modulated in a timedependent manner by the absence of CCR5 during the course of chronic fungal asthma disease.

\section{Transient goblet cell hyperplasia in A. fumigatus-sensitized CCR5-/- mice following a challenge with conidia}

Figure 7 summarizes the temporal changes in goblet cell hyperplasia present in A. fumigatussensitized mice CCR5+/+ and CCR5-/- mice at various times after a conidia challenge. Neither group of mice exhibited goblet cell hyperplasia before the conidia challenge (not shown). The histological picture at day 2 revealed that goblet cells were much more prominent in the CCR5+/+ group (Fig. 7A) than in the CCR5-/- groups (Fig. 7B). At day 12 after conidia, goblet cell hyperplasia was a prominent feature in CCR5+/+ mice (Fig. 7C) and CCR5-/- mice (Fig. 7D). Histological analysis at day 21 after the conidia challenge revealed that goblet cells were prominent in the airways of CCR5+/+ mice (Fig. 7E), no evidence of goblet cell hyperplasia was observed in CCR5-/- mice (Fig. 7F). Similarly at day 40 after the conidia challenge, the airways of CCR5+/+ mice (Fig. 7G) contained goblet cells, whereas the airways of CCR5-/- mice did not (Fig. 7H). Thus, goblet cell hyperplasia was present only in CCR5-/- mice at day 12 after the conidia challenge.

\section{CCR5-/- mice exhibit significantly less peribronchial fibrosis than CCR5+/+ mice at day 30 after a conidia challenge}

Previous studies have shown that the peribronchial fibrotic process is most pronounced at day 30 after a conidia challenge (36). In the present study, we examined the levels of collagen in whole lung homogenates from CCR5+/+ and CCR5-/- mice at day 30 after conidia (Fig. 8). At this time, total soluble collagen levels in A. fumigatus-sensitized mice were increased approximately 10 -fold above those in nonsensitized mice (dashed line Fig. 8). Total soluble collagen levels in whole lung homogenates from CCR5-/- mice were approximately 4-fold $(P=0.0329)$ lower than collagen levels in CCR5+/+ mice. These findings suggested that pulmonary airway remodeling in the form of peribronchial fibrosis was impaired in CCR5-/- mice during chronic fungal asthma.

\section{Whole lung levels of IL-4 and IFN- $\gamma$ in A. fumigatus-sensitized CCR5+/+ and CCR5-/- mice following a challenge with conidia}

Zhou et al. (40) have shown that IL-4 and IFN- $\gamma$ synthesis by CCR5-/- T-cells is significantly enhanced compared with CCR5+/+ T-cells. In the present study, we examined whether the 
transient expression of fungal asthma in CCR5-/- mice was related to changes in IL-4 and IFN- $\gamma$.

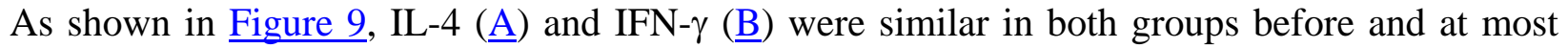
times after conidia. The exceptions were observed at day 2 after conidia when whole lung homogenates from CCR5-/- mice contained significantly less immunoreactive IL-4 and IFN- $\gamma$ (Fig. 9A, B, respectively). In addition, at day 40 after conidia, whole lung homogenates from CCR5-/- mice contained significantly less IL-4 than similar samples from CCR5+/+ mice (Fig. 9A). Overall, it did not appear that differences in whole lung levels of IL-4 and IFN- $\gamma$ accounted for the transient nature of the fungal asthma in CCR5-/- mice.

\section{Immunoneutralization of RANTES/CCL5 during the first 12 days after the conidia challenge moderated fungal asthma in CCR5+/+ and CCR5-/- mice}

The role of RANTES in the context of the CCR5-/- mouse was determined by immunoneutralization from day 0-12 after conidia challenge after which AHR was assessed and serum and lung samples were removed for analysis. Passive neutralization of RANTES/CCL5 significantly reduced airway resistance in both CCR5+/+ and CCR5-/- mice (Figure 10). Histological analysis showed resolution of inflammation throughout the CCR5+/+ and CCR5-/lungs after anti-RANTES treatment with clear reduction of eosinophil and lymphocyte accumulation around both airways and blood vessels (Fig. 11). The recruitment of lymphocytes and eosinophils to the airways of CCR5-/- mice at day 12 was RANTES/CCL5-dependent as revealed by the BAL leukocyte counts (Figure 12) of mice that received anti-RANTES/CCL5 antibodies. This was presumably due to the ability of RANTES to bind an alternative receptor. Future studies are intended to clarify the identity of this alternative receptor.

\section{DISCUSSION}

CCR5 is a chemokine receptor for MIP-1 $\alpha / C C L 3$, MIP-1 $\beta / C C L 4$, and RANTES/CCL5 (42) (3). A natural mutation in CCR5 exists and individuals who are homozygous for a 32-base pair deletion in the coding sequence of CCR5 (CCR5 32 ) were found to be highly resistant to HIV infection (4) and potentially other chronic diseases such as asthma (7). In the present study, we examined the contribution of CCR5 and RANTES/CCL5 to the development and maintenance of chronic fungal asthma induced by A. fumigatus conidia in A. fumigatus-sensitized mice. Experimental studies using acute models of allergic airway disease have corroborated these clinical findings by showing that RANTES/CCL5 is a major eosinophil (30) and T-cell chemoattractant $(31,32)$ that consequently modulates airway hyperresponsiveness $(32)$. The role of RANTES/CCL5 in allergic wild-type mice has been examined by using antibody immunoneutralization techniques, but a description of allergic airway disease in CCR5-/- mice has not been reported previously. We observed that the appearance of fungal asthma in $A$. fumigatus-sensitized CCR5-/- mice was transient; allergic airway disease was observed only at one of the four time points examined after the introduction of conidia. In addition, RANTES/CCL5 appeared to mediate this transient appearance of fungal asthma in A. fumigatussensitized CCR5-/- mice, possibly through one or more of its alternative receptors-CCR1, CCR3, and CCR4. Taken together, these data suggest that CCR5 and RANTES/CCL5 are key contributors to the development and maintenance of chronic fungal asthma in mice. 
The compilation of previous studies of immune responses by CCR5-/- mice results in a complex and multi-layered schema in which the involvement of CCR5 depends on the nature of the pathogen (i.e., bacterial, viral, or fungal), the site of infection, and the background strain of the CCR5-/- mouse. For example, Zhou et al. (40) demonstrated that CCR5-/- mice (on an ICR background) shared similar developmental qualities with their wild-type counterparts. This study also showed that CCR5-/- mice exhibited a defect in the innate immune response necessary for clearing Listeria from the liver (but not lung and spleen), whereas T-cell-dependent delayed-type hypersensitivity reactions and humoral responses were enhanced markedly in these mice. These latter findings agree with data from the present study, which revealed that A. fumigatussensitized CCR5-/- mice had significantly higher serum levels of IgE before the conidia challenge compared with CCR5+/+ mice at the same time. However, serum IgE levels in these mice were comparable in both groups at all other times, except day 40 after conidia. Nonsensitized CCR5-/- mice (on a C57BL/6Jx129/Ola background) effectively resisted pulmonary infection with Cryptococcus neoformans but were susceptible to brain infection due to a lack of leukocyte recruitment into the brain (43). CCR5-/- mice on the same genetic background appeared to be susceptible to the lethal effects of a primary pulmonary influenza infection; this response appeared to be related to a massive inflammatory response rather than the cytopathic effects of an increased viral burden (44). However, other studies suggest that CCR5-/mice (on a C57BL/6x129/Ola background) effectively clear or contain systemic and pulmonary pathogens such as Leishmania donovani (45) without any apparent or persistent immune abnormality. In the present study, A. fumigatus conidia were rapidly cleared from the airways of A. fumigatus-sensitized CCR5-/- mice compared with similarly sensitized CCR5+/+ mice. Both macrophages and neutrophils are required for the clearance of A. fumigatus from the airways of mice $(46,47)$, and comparable or significantly increased ( $\mathrm{P} \leq 0.05$ compared with CCR5+/+ mice) numbers of both leukocyte populations were observed after the conidia challenge in $A$. fumigatus-sensitized CCR5-/- mice. Our previous studies showed that neutrophil recruitment was impaired severely following a conidia challenge in A. fumigatus-sensitized CCR2-/- mice, and consequently CCR2-/- mice retained the conidia and developed severe allergic disease (38).

RANTES/CCL5 was discovered by subtractive hybridization as a T-cell-specific sequence (48). It was initially shown to be a major chemoattractant for monocytes, memory T-cells (49), and eosinophils (50) particularly after an intranasal or intrapulmonary allergen challenge (14, 19, 21 , 51) (52). Constitutive and induced expression of RANTES/CCL5 has been described in airway epithelial cells (53), fibroblasts (54) (55), endothelial cells (56), smooth muscle cells (57), and eosinophils (52). All of these cell types appear to contribute to the increased levels of this CC chemokine, detected in the airways of patients with atopic (17) and non-atopic (22) asthma. Although its appearance was delayed compared with the CCR5+/+ group, airway hyperresponsiveness to methacholine was expressed transiently at day 12 after the conidia challenge in A. fumigatus-sensitized CCR5-/- mice. The recruitment of lymphocytes and eosinophils into and around the airways of CCR5-/- mice at day 12 was RANTES/CCL5dependent (as revealed by the BAL leukocyte counts in the passive immunoneutralization of RANTES/CCL5), presumably through its ability to bind CCR1, CCR3, and/or CCR4 (58) (33). Analysis of the possible compensatory role of these alternative receptors for RANTES is the subject of ongoing studies. 
CCR5 is expressed abundantly on T-cells from non-asthmatics and mild asthmatics (2). Originally, CCR5 was characterized as a surface marker of human T-cells producing Th1 cytokines, but CCR5 expression is not essential for differentiation of human Th1 cells (11). Th1 cells appear to preferentially express CCR5 and CXCR3 whereas Th2 cells preferentially express CCR4 and, to a lesser extent, CCR3 (10). More recent data have shown that such chemokine receptor distinctions between Th1 and Th2 cells may not be present in vivo (12). CCR5-/- mice exhibit a defect in IFN- $\gamma$ production during acute Leishmania donovani infection but enhance IFN- $\gamma$ production during a chronic challenge with this intracellular microbe (45). These observations corresponded with our findings that whole lung levels of IFN- $\gamma$ were similar or significantly higher (i.e., at day 2 after conidia) in CCR5-/- mice compared with CCR5+/+ mice. We also noted that IL-4 was similar or significantly lower (i.e., at days 2 and 40 after conidia) in CCR5-/- mice compared with their wild-type counterparts. The findings from the present study suggest that the Th cytokine profile in CCR5-/- mice does not shift dramatically during the development of chronic fungal asthma.

Airway remodeling generally refers to the structural changes that occur in the asthmatic airway as a result of ongoing Th2 cytokine-mediated inflammation $(59,60)$. These changes include epithelial and goblet cell hyperplasia; smooth-muscle hypertrophy; and, in some cases, pronounced sub-epithelial fibrosis (61-63). All of these features are present at various times after the conidia challenge in A. fumigatus-sensitized mice (36). However, we noted in the present study that goblet cell hyperplasia was detected at day 12 only after conidia in A. fumigatussensitized CCR5-/- mice. Total soluble collagen was measured at day 30 after the conidia challenge to coincide with the time of peak peribronchial fibrosis in this model (36). The immunoneutralization of RANTES/CCL5 did not prevent the appearance of goblet cells in the airways of CCR5-/- mice at day 12. However, peribronchial fibrosis in CCR5-/- mice was significantly decreased at day 30 after the conidia challenge compared with the CCR5+/+ mice at the same time, and RANTES/CCL5 neutralization decreased early (day 12) collagen deposition in both CCR5+/+ and CCR5-/- mice. Thus, the development of airway remodeling was dependent in part, but not in whole, on RANTES/CCL5 and CCR5 during chronic fungal asthma.

In conclusion, the results from the present study demonstrate the major role of RANTES/CCL5 and CCR5 in a chronic model of fungal asthma. Although the lack of CCR5 markedly restricted the development of fungal asthma, it was apparent that its major ligand could function in its absence. Such findings highlight the complexity of chemokine-chemokine receptor interactions during chronic diseases and suggest that limiting the expression or function of RANTES/CCL5, rather than antagonizing CCR5, may be a more successful strategy in the treatment of clinical asthma.

\section{ACKNOWLEDGMENTS}

The authors thank Gary Huffnagle for providing a portion of the CCR5-/- and CCR5+/+ mice that were used in these studies. ELISA reagents were kindly provided by Steven L. Kunkel. This study was supported in part by an American Lung Association Research grant (CMH). 


\section{REFERENCES}

1. Murdoch, C. and Finn, A. (2000) Chemokine receptors and their role in inflammation and infectious diseases. Blood 95, 3032-3043

2. Campbell, J. J., Brightling, C. E., Symon, F. A., Qin, S., Murphy, K. E., Hodge, M., Andrew, D. P., Wu, L., Butcher, E. C., and Wardlaw, A. J. (2001) Expression of chemokine receptors by lung $\mathrm{T}$-cells from normal and asthmatic subjects. J. Immunol. 166, 2842-2848

3. Raport, C. J., Gosling, J., Schweickart, V. L., Gray, P. W., and Charo, I. F. (1996) Molecular cloning and functional characterization of a novel human $\mathrm{CC}$ chemokine receptor (CCR5) for RANTES, MIP-1beta, and MIP-1alpha. J. Biol. Chem. 271, 1716117166

4. Huang, Y., Paxton, W. A., Wolinsky, S. M., Neumann, A. U., Zhang, L., He, T., Kang, S., Ceradini, D., Jin, Z., Yazdanbakhsh, K., Kunstman, K., Erickson, D., Dragon, E., Landau, N. R., Phair, J., Ho, D. D., and Koup, R. A. (1996) The role of a mutant CCR5 allele in HIV-1 transmission and disease progression [see comments]. Nat. Med. 2, 12401243

5. Stewart, G. J., Ashton, L. J., Biti, R. A., French, R. A., Bennetts, B. H., Newcombe, N. R., Benson, E. M., Carr, A., Cooper, D. A., and Kaldor, J. M. (1997) Increased frequency of CCR-5 delta 32 heterozygotes among long-term non-progressors with HIV-1 infection. The Australian Long-Term Non-Progressor Study Group. Aids 11, 1833-1838

6. Zapico, I., Coto, E., Rodriguez, A., Alvarez, C., Torre, J. C., and Alvarez, V. (2000) CCR5 (chemokine receptor-5) DNA-polymorphism influences the severity of rheumatoid arthritis. Genes Immun. 1, 288-289

7. Hall, I. P., Wheatley, A., Christie, G., McDougall, C., Hubbard, R., and Helms, P. J. (1999) Association of CCR5 delta32 with reduced risk of asthma [letter] [see comments]. Lancet 354, 1264-1265

8. Szalai, C., Bojszko, A., Beko, G., and Falus, A. (2000) Prevalence of CCR5delta32 in allergic diseases. Lancet 355, 66

9. Mitchell, T. J., Walley, A. J., Pease, J. E., Venables, P. J., Wiltshire, S., Williams, T. J., and Cookson, W. O. (2000) Delta 32 deletion of CCR5 gene and association with asthma or atopy. Lancet 356, 1491-1492

10. Bonecchi, R., Bianchi, G., Bordignon, P. P., D'Ambrosio, D., Lang, R., Borsatti, A., Sozzani, S., Allavena, P., Gray, P. A., Mantovani, A., and Sinigaglia, F. (1998) Differential expression of chemokine receptors and chemotactic responsiveness of type 1 T helper cells (Th1s) and Th2s. J. Exp. Med. 187, 129-134 
11. Odum, N., Bregenholt, S., Eriksen, K. W., Skov, S., Ryder, L. P., Bendtzen, K., Van Neerven, R. J., Svejgaard, A., and Garred, P. (1999) The CC-chemokine receptor 5 (CCR5) is a marker of, but not essential for the development of human Th1 cells. Tissue Antigens 54, 572-577

12. Nanki, T. and Lipsky, P. E. (2001) Lack of correlation between chemokine receptor and Th1/Th2 cytokine expression by individual memory T-cells. Int. Immun. 12, 1659-1667

13. Alam, R., York, J., Boyars, M., Stafford, S., Grant, J. A., Lee, J., Forsythe, P., Sim, T., and Ida, N. (1996) Increased MCP-1, RANTES, and MIP-1alpha in bronchoalveolar lavage fluid of allergic asthmatic patients. Am. J. Respir. Crit. Care Med. 153, 13981404

14. Holgate, S. T., Bodey, K. S., Janezic, A., Frew, A. J., Kaplan, A. P., and Teran, L. M. (1997) Release of RANTES, MIP-1 alpha, and MCP-1 into asthmatic airways following endobronchial allergen challenge. Am. J. Respir. Crit. Care Med. 156, 1377-1383

15. Humbert, M., Ying, S., Corrigan, C., Menz, G., Barkans, J., Pfister, R., Meng, Q., Van Damme, J., Opdenakker, G., Durham, S. R., and Kay, A. B. (1997) Bronchial mucosal expression of the genes encoding chemokines RANTES and MCP-3 in symptomatic atopic and nonatopic asthmatics: relationship to the eosinophil-active cytokines interleukin (IL)-5, granulocyte macrophage-colony-stimulating factor, and IL-3. Am. J. Respir. Cell Mol. Biol. 16, 1-8

16. Powell, N., Humbert, M., Durham, S. R., Assoufi, B., Kay, A. B., and Corrigan, C. J. (1996) Increased expression of mRNA encoding RANTES and MCP-3 in the bronchial mucosa in atopic asthma. Eur. Respir. J. 9, 2454-2460

17. Berkman, N., Krishnan, V. L., Gilbey, T., Newton, R., O'Connor, B., Barnes, P. J., and Chung, K. F. (1996) Expression of RANTES mRNA and protein in airways of patients with mild asthma. Am. J. Respir. Crit. Care Med. 154, 1804-1811

18. Chihara, J., Yasuba, H., Tsuda, A., Urayama, O., Saito, N., Honda, K., Kayaba, H., Yamashita, T., Kurimoto, F., and Yamada, H. (1997) Elevation of the plasma level of RANTES during asthma attacks. J. Allergy Clin. Immunol. 100, S52-55

19. Teran, L. M., Noso, N., Carroll, M., Davies, D. E., Holgate, S., and Schroder, J. M. (1996) Eosinophil recruitment following allergen challenge is associated with the release of the chemokine RANTES into asthmatic airways. J. Immunol. 157, 1806-1812

20. Ying, S., Meng, Q., Zeibecoglou, K., Robinson, D. S., Macfarlane, A., Humbert, M., and Kay, A. B. (1999) Eosinophil chemotactic chemokines (eotaxin, eotaxin-2, RANTES, monocyte chemoattractant protein-3 (MCP-3), and MCP-4), and $\mathrm{C}-\mathrm{C}$ chemokine receptor 3 expression in bronchial biopsies from atopic and nonatopic (Intrinsic) asthmatics. $J$. Immunol. 163, 6321-6329 
21. Venge, J., Lampinen, M., Hakansson, L., Rak, S., and Venge, P. (1996) Identification of IL-5 and RANTES as the major eosinophil chemoattractants in the asthmatic lung. $J$. Allergy Clin. Immunol. 97, 1110-1115

22. Folkard, S. G., Westwick, J., and Millar, A. B. (1997) Production of interleukin-8, RANTES and MCP-1 in intrinsic and extrinsic asthmatics. Eur. Respir. J. 10, 2097-2104

23. Tillie-Leblond, I., Hammad, H., Desurmont, S., Pugin, J., Wallaert, B., Tonnel, A. B., and Gosset, P. (2000) CC chemokines and interleukin-5 in bronchial lavage fluid from patients with status asthmaticus. Potential implication in eosinophil recruitment [In Process Citation]. Am. J. Respir. Crit. Care Med. 162, 586-592

24. Hajeer, A. H., al Sharif, F., and Ollier, W. E. (1999) A polymorphism at position -403 in the human RANTES promoter. Eur. J. Immunogenet. 26, 375-376

25. Marshall, H. (2001) RANTES polymorphism affects susceptibility to HIV and asthma. Trends Immunol. 22, 13

26. Fryer, A. A., Spiteri, M. A., Bianco, A., Hepple, M., Jones, P. W., Strange, R. C., Makki, R., Tavernier, G., Smilie, F. I., Custovic, A., Woodcock, A. A., Ollier, W. E., and Hajeer, A. H. (2000) The -403 G-->A promoter polymorphism in the RANTES gene is associated with atopy and asthma. Genes Immun. 1, 509-514

27. Kawai, T., Seki, M., Hiromatsu, K., Eastcott, J. W., Watts, G. F., Sugai, M., Smith, D. J., Porcelli, S. A., and Taubman, M. A. (1999) Selective diapedesis of Th1 cells induced by endothelial cell RANTES. J. Immunol. 163, 3269-3278

28. Siveke, J. T. and Hamann, A. (1998) T helper 1 and $\mathrm{T}$ helper 2 cells respond differentially to chemokines. J. Immunol. 160, 550-554

29. Zang, Y. C., Samanta, A. K., Halder, J. B., Hong, J., Tejada-Simon, M. V., Rivera, V. M., and Zhang, J. Z. (2000) Aberrant T-cell migration toward RANTES and MIP-1alpha in patients with multiple sclerosis: overexpression of chemokine receptor CCR5 [In Process Citation]. Brain 123, 1874-1882

30. Lukacs, N. W., Standiford, T. J., Chensue, S. W., Kunkel, R. G., Strieter, R. M., and Kunkel, S. L. (1996) C-C chemokine-induced eosinophil chemotaxis during allergic airway inflammation. J. Leukoc. Biol. 60, 573-578

31. Gonzalo, J. A., Lloyd, C. M., Kremer, L., Finger, E., Martinez, A. C., Siegelman, M. H., Cybulsky, M., and Gutierrez-Ramos, J. C. (1996) Eosinophil recruitment to the lung in a murine model of allergic inflammation. The role of T-cells, chemokines, and adhesion receptors. J. Clin. Invest. 98, 2332-2345

32. Gonzalo, J. A., Lloyd, C. M., Wen, D., Albar, J. P., Wells, T. N., Proudfoot, A., Martinez, A. C., Dorf, M., Bjerke, T., Coyle, A. J., and Gutierrez-Ramos, J. C. (1998) 
The coordinated action of $\mathrm{CC}$ chemokines in the lung orchestrates allergic inflammation and airway hyperresponsiveness. J. Exp. Med. 188, 157-167

33. Pakianathan, D. R., Kuta, E. G., Artis, D. R., Skelton, N. J., and Hebert, C. A. (1997) Distinct but overlapping epitopes for the interaction of a CC-chemokine with CCR1, CCR3 and CCR5. Biochemistry 36, 9642-9648

34. Elsner, J., Petering, H., Hochstetter, R., Kimmig, D., Wells, T. N., Kapp, A., and Proudfoot, A. E. (1997) The CC chemokine antagonist Met-RANTES inhibits eosinophil effector functions through the chemokine receptors CCR1 and CCR3. Eur. J. Immunol. 27, 2892-2898

35. Power, C. A., Meyer, A., Nemeth, K., Bacon, K. B., Hoogewerf, A. J., Proudfoot, A. E., and Wells, T. N. (1995) Molecular cloning and functional expression of a novel CC chemokine receptor cDNA from a human basophilic cell line. J. Biol. Chem. 270, 1949519500

36. Hogaboam, C. M., Blease, K., Mehrad, B., Steinhauser, M. L., Standiford, T. J., Kunkel, S. L., and Lukacs, N. W. (2000) Chronic airway hyperreactivity, goblet cell hyperplasia, and peribronchial fibrosis during allergic airway disease induced by Aspergillus fumigatus. Am. J. Pathol. 156, 723-732

37. Blease, K., Mehrad, B., Standiford, T. J., Lukacs, N. W., Kunkel, S. L., Chensue, S. W., Lu, B., Gerard, C. J., and Hogaboam, C. M. (2000) Airway remodeling is absent in CCR1-/- mice during chronic fungal allergic airway disease. J. Immunol. 165, 1564-1572

38. Blease, K., Mehrad, B., Standiford, T. J., Lukacs, N. W., Gosling, J., Boring, L., Charo, I. F., Kunkel, S. L., and Hogaboam, C. M. (2000) Enhanced pulmonary allergic responses to Aspergillus in CCR2-/- mice. J. Immunol. 165, 2603-2611

39. Evanoff, H., Burdick, M. D., Moore, S. A., Kunkel, S. L., and Strieter, R. M. (1992) A sensitive ELISA for the detection of human monocyte chemoattractant protein-1 (MCP1). Immunol. Invest. 21, 39-49

40. Zhou, Y., Kurihara, T., Ryseck, R. P., Yang, Y., Ryan, C., Loy, J., Warr, G., and Bravo, R. (1998) Impaired macrophage function and enhanced T-cell-dependent immune response in mice lacking CCR5, the mouse homologue of the major HIV-1 coreceptor. $J$. Immunol. 160, 4018-4025

41. Blanpain, C., Migeotte, I., Lee, B., Vakili, J., Doranz, B. J., Govaerts, C., Vassart, G., Doms, R. W., and Parmentier, M. (1999) CCR5 binds multiple CC-chemokines: MCP-3 acts as a natural antagonist. Blood 94, 1899-1905

42. Huffnagle, G. B., McNeil, L. K., McDonald, R. A., Murphy, J. W., Toews, G. B., Maeda, N., and Kuziel, W. A. (1999) The role of CCR5 in organ-specific and innate immunity to Cryptococcus neoformans. J. Immunol. 163, 4642-4646 
43. Dawson, T. C., Beck, M. A., Kuziel, W. A., Henderson, F., and Maeda, N. (2000) Contrasting effects of CCR5 and CCR2 deficiency in the pulmonary inflammatory response to influenza A virus. Am. J. Pathol. 156, 1951-1959

44. Sato, N., Kuziel, W. A., Melby, P. C., Reddick, R. L., Kostecki, V., Zhao, W., Maeda, N., Ahuja, S. K., and Ahuja, S. S. (1999) Defects in the generation of IFN-gamma are overcome to control infection with Leishmania donovani in CC chemokine receptor (CCR) 5-, macrophage inflammatory protein-1 alpha-, or CCR2-deficient mice. $J$. Immunol. 163, 5519-5525

45. Mehrad, B., Strieter, R. M., Moore, T. A., Tsai, W. C., Lira, S. A., and Standiford, T. J. (1999) CXC chemokine receptor-2 ligands are necessary components of neutrophilmediated host defense in invasive pulmonary aspergillosis. J. Immunol. 163, 6086-6094

46. Mehrad, B., Moore, T. A., and Standiford, T. J. (2000) Macrophage inflammatory protein-1 alpha is a critical mediator of host defense against invasive pulmonary aspergillosis in neutropenic hosts. J. Immunol. 165, 962-968

47. Schall, T. J., Jongstra, J., Dyer, B. J., Jorgensen, J., Clayberger, C., Davis, M. M., and Krensky, A. M. (1988) A human T-cell-specific molecule is a member of a new gene family. J. Immunol. 141, 1018-1025

48. Schall, T. J., Bacon, K., Toy, K. J., and Goeddel, D. V. (1990) Selective attraction of monocytes and $\mathrm{T}$ lymphocytes of the memory phenotype by cytokine RANTES. Nature (London) 347, 669-671

49. Alam, R., Stafford, S., Forsythe, P., Harrison, R., Faubion, D., Lett-Brown, M. A., and Grant, J. A. (1993) RANTES is a chemotactic and activating factor for human eosinophils. J. Immunol. 150, 3442-3448

50. Lampinen, M., Rak, S., and Venge, P. (1999) The role of interleukin-5, interleukin-8 and RANTES in the chemotactic attraction of eosinophils to the allergic lung [see comments]. Clin. Exp. Allergy 29, 314-322

51. Chihara, J., Oyamada, H., Yamada, H., Tsuda, A., Kamada, Y., and Urayama, O. (1997) Expression of mRNA for RANTES in human eosinophils. Int. Arch. Allergy Immunol. 114 Suppl 1, 33-35

52. Becker, S., Reed, W., Henderson, F. W., and Noah, T. L. (1997) RSV infection of human airway epithelial cells causes production of the beta-chemokine RANTES. Am. J. Physiol. 272, L512-520

53. Maune, S., Werner, J. A., Sticherling, M., and Schroder, J. M. (1997) Fibroblasts obtained from human nasal, laryngeal and tracheal mucosa produce the chemokine RANTES. Otolaryngol. Pol. 51, 3-10 
54. Michelson, S., Dal Monte, P., Zipeto, D., Bodaghi, B., Laurent, L., Oberlin, E., Arenzana-Seisdedos, F., Virelizier, J. L., and Landini, M. P. (1997) Modulation of RANTES production by human cytomegalovirus infection of fibroblasts. J. Virol. 71, 6495-6500

55. Terada, N., Maesako, K., Hamano, N., Ikeda, T., Sai, M., Yamashita, T., Fukuda, S., and Konno, A. (1996) RANTES production in nasal epithelial cells and endothelial cells. $J$. Allergy Clin. Immunol. 98, S230-237

56. Pype, J. L., Dupont, L. J., Menten, P., Van Coillie, E., Opdenakker, G., Van Damme, J., Chung, K. F., Demedts, M. G., and Verleden, G. M. (1999) Expression of monocyte chemotactic protein (MCP)-1, MCP-2, and MCP-3 by human airway smooth-muscle cells. Modulation by corticosteroids and T-helper 2 cytokines. Am. J. Respir. Cell Mol. Biol. 21, 528-536

57. Chensue, S. W., Warmington, K. S., Allenspach, E. J., Lu, B., Gerard, C., Kunkel, S. L., and Lukacs, N. W. (1999) Differential expression and cross-regulatory function of RANTES during mycobacterial (type 1) and schistosomal (type 2) antigen-elicited granulomatous inflammation. J. Immunol. 163, 165-173

58. Fahy, J. V., Corry, D. B., and Boushey, H. A. (2000) Airway inflammation and remodeling in asthma. Curr. Opin. Pulm. Med. 6, 15-20

59. Djukanovic, R. (2000) Asthma: A disease of inflammation and repair. J. Allergy Clin. Immunol. 105, 522-526

60. Elias, J. A., Zhu, Z., Chupp, G., and Homer, R. J. (1999) Airway remodeling in asthma. J. Clin. Invest. 104, 1001-1006

61. Bento, A. M. and Hershenson, M. B. (1998) Airway remodeling: potential contributions of subepithelial fibrosis and airway smooth muscle hypertrophy/hyperplasia to airway narrowing in asthma. Allergy Asthma Proc. 19, 353-358

62. Hoshino, M., Nakamura, Y., Sim, J., Shimojo, J., and Isogai, S. (1998) Bronchial subepithelial fibrosis and expression of matrix metalloproteinase-9 in asthmatic airway inflammation. J. Allergy Clin. Immunol. 102, 783-788 
Fig. 1

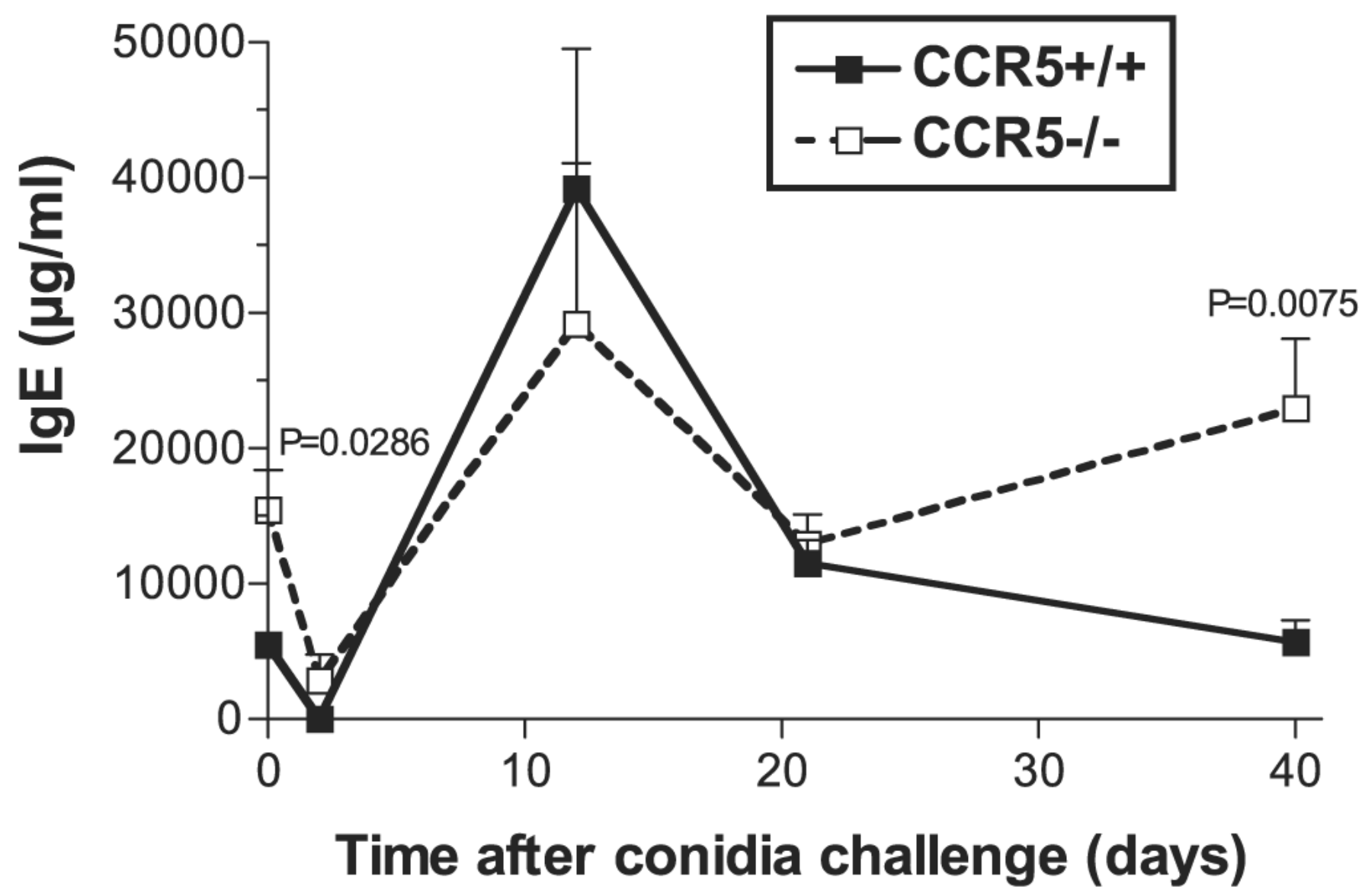

Figure 1. Serum IgE levels in A. fumigatus-sensitized C-C chemokine receptor-5 (CCR5) wild-type (+/+) and CCR5 knockout (-/-) mice before and during various times after $A$. fumigatus conidia challenge. Significant differences between the two groups were detected before and at day 40 after the conidia challenge. Total IgE was measured by using a specific ELISA as described in Materials and Methods. Data are expressed as mean \pm SE; $n=4-7 /$ group/time point. 
Fig. 2

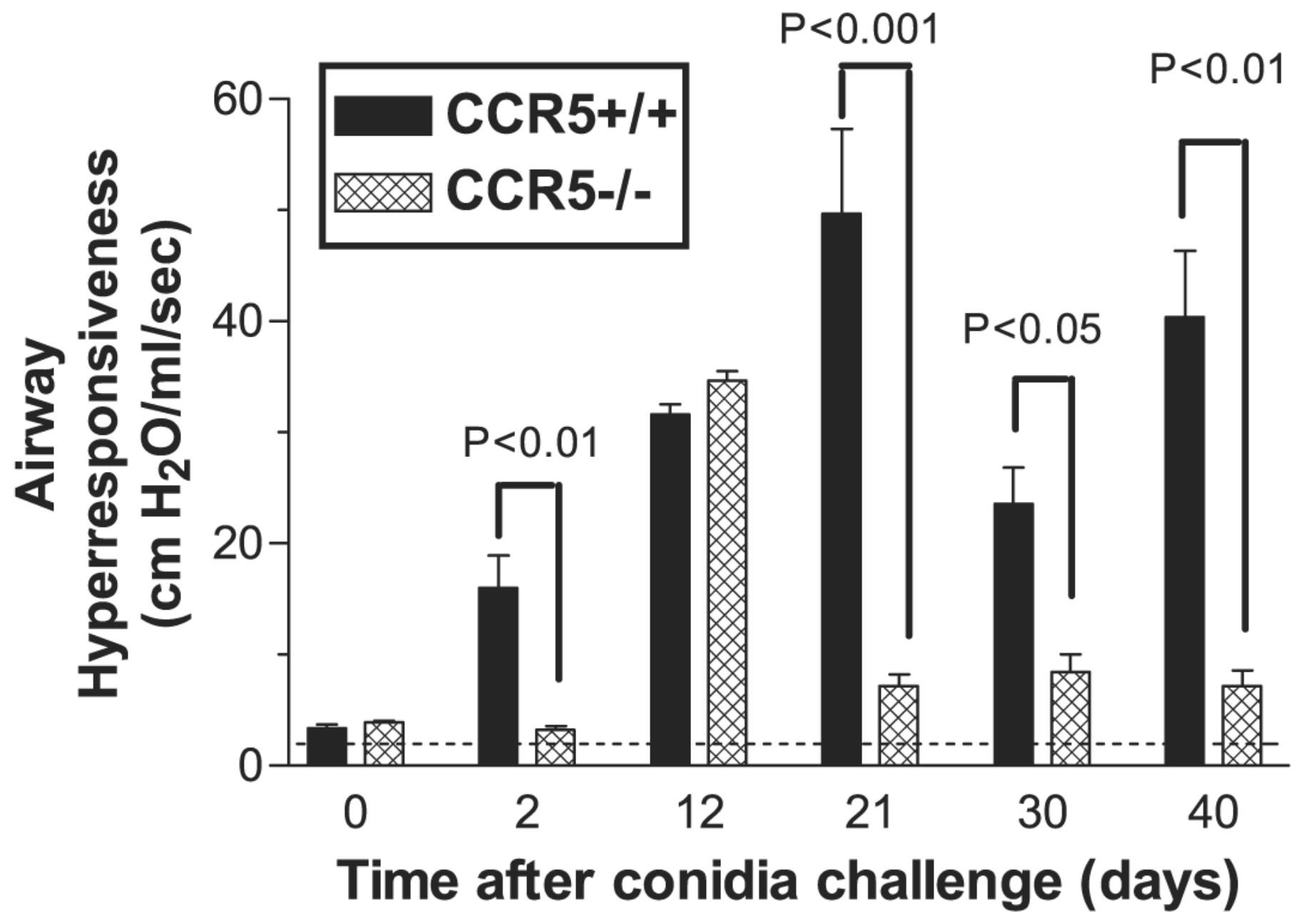

Figure 2. Airway hyperresponsiveness in A. fumigatus-sensitized C-C chemokine receptor-5 (CCR5) wild-type $(+/+)$ and CCR5 knockout (-/-) mice before and during various times after an intrapulmonary challenge with live A. fumigatus conidia. Peak increases in airway resistance or hyperresponsiveness (units $=\mathrm{cm} \mathrm{H}_{2} \mathrm{O} / \mathrm{ml} / \mathrm{s}$ ) were determined at each time point after the intravenous injection of methacholine. Values are expressed as mean $\pm \mathrm{SE} ; n=4-7$ /group/time point. 
Fig. 3

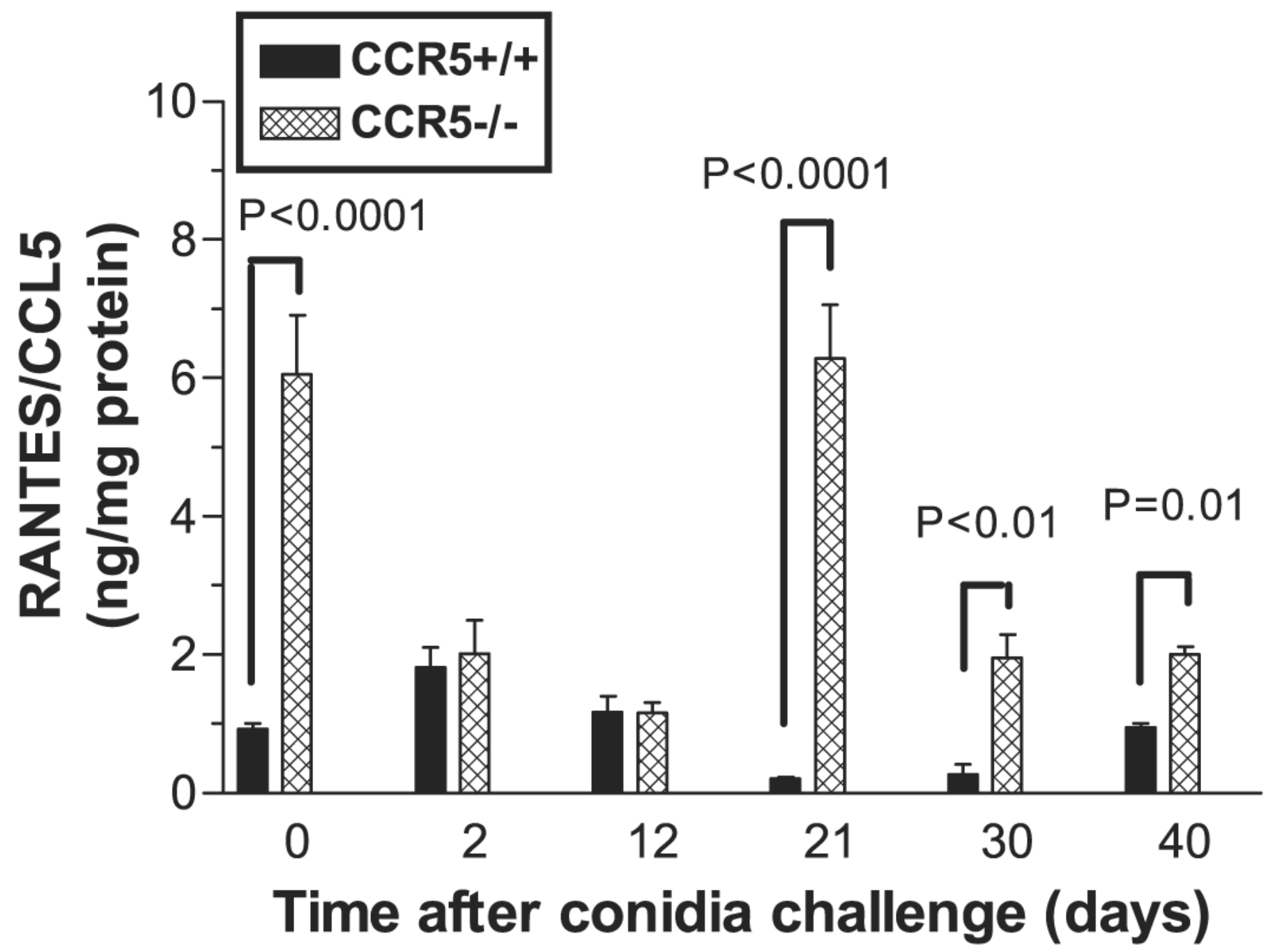

Figure 3. RANTES/CCL5 levels in whole lung homogenates from A. fumigatus-sensitized C-C chemokine receptor-5 (CCR5) wild-type (+/+) and CCR5 knockout (-/-) mice before and during various times after a live $A$. fumigatus conidia challenge. Cytokine levels were measured by using a specific ELISA as described in Materials and Methods. Values are expressed as mean \pm SE; $n=4-7$ mice/group/time point. 
Fig. 4
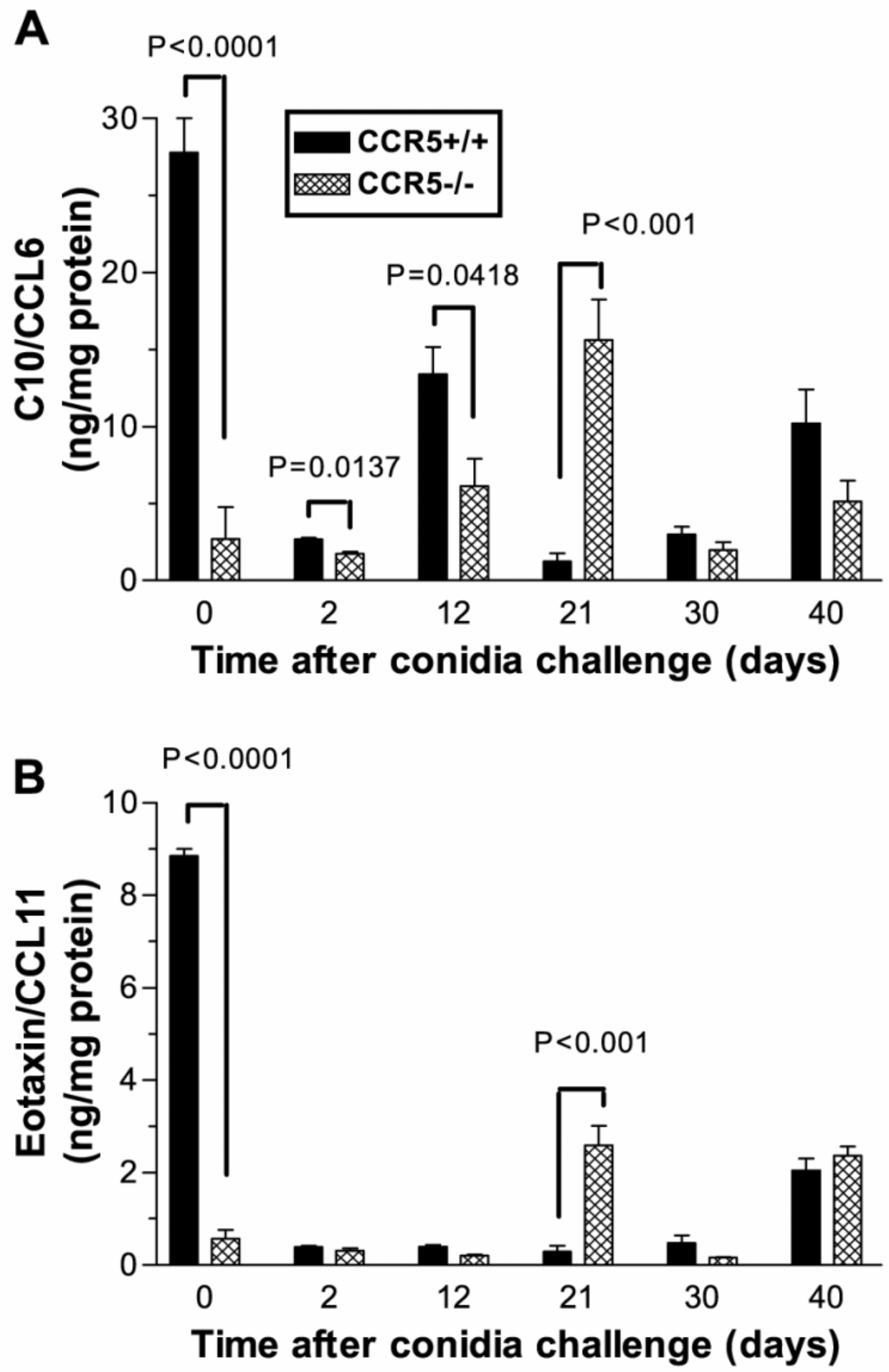

Figure 4. C10/CCL6 (A) and eotaxin/CCL11 (B) levels in whole lung homogenates from A. fumigatus-sensitized CC chemokine receptor-5 (CCR5) wild-type (+/+) and CCR5 knockout (-/-) mice before and during various times after a live A. fumigatus conidia challenge. Cytokine levels were measured by using a specific ELISA as described in Materials and Methods. Values are expressed as mean \pm SE; $n=4-7$ mice/group/time point. 
Fig. 5

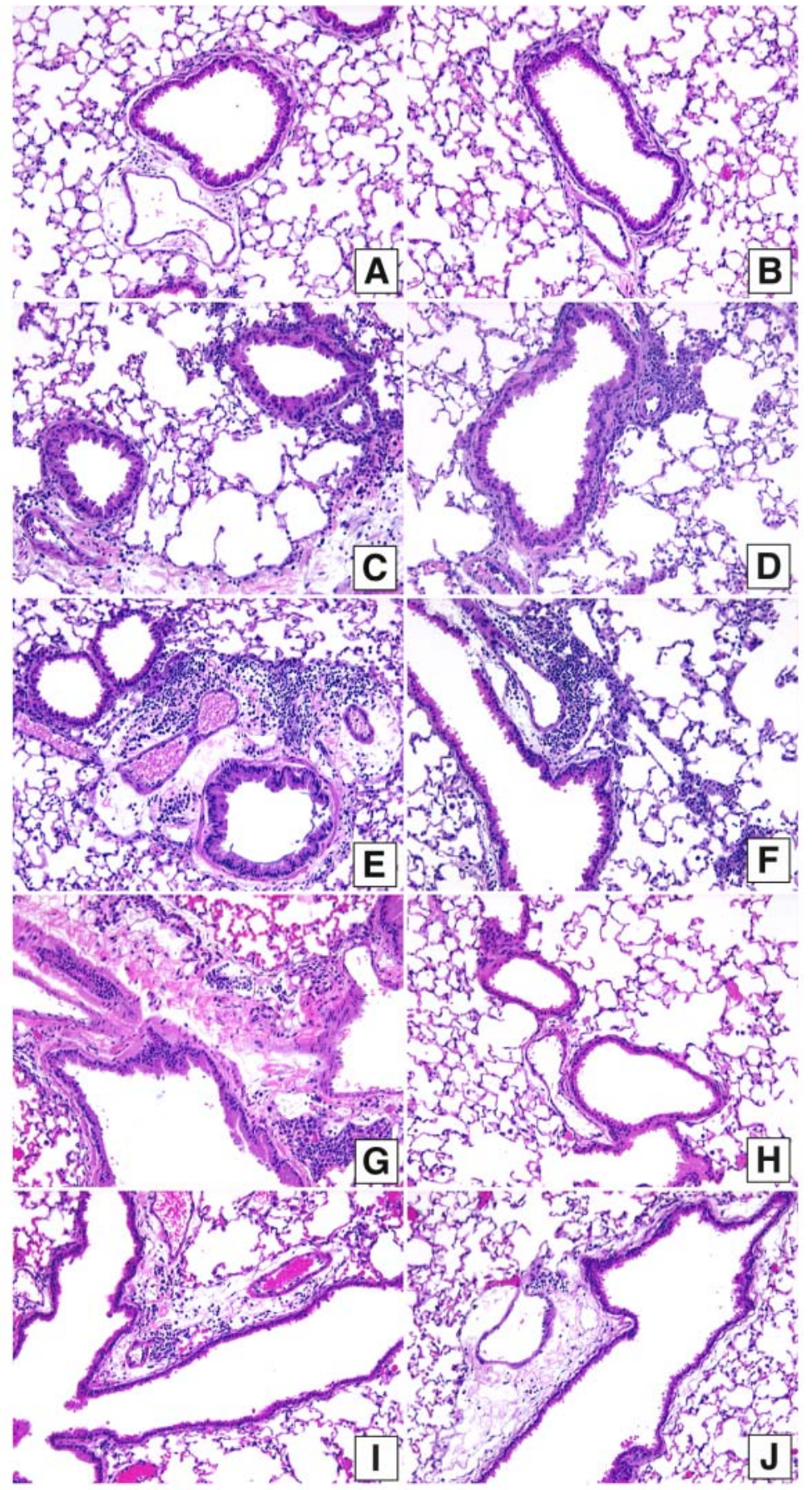

Figure 5. Representative photomicrographs of hematoxylin and eosin-stained whole lung sections from $A$. fumigatus-sensitized C-C chemokine receptor-5 (CCR5) wild-type (+/+) and CCR5 knockout (-/-) mice before and during various times after a live $A$. fumigatus conidia challenge. Little evidence of peribronchial inflammation was observed in CCR5+/+ mice (A) and CCR5-/- mice (B) before the conidia challenge. At day 2 after conidia, CCR5+/+ mice (C) exhibited perivascular and peribronchial inflammation, whereas CCR5-/- mice (D) exhibited perivascular inflammation alone. At day 12 after conidia, intense peribronchial inflammation was observed in both groups of mice (E, F). At day 21 after conidia, peribronchial inflammation and fibrosis (note pink spindle-shaped cells around airways) were observed in CCR5+/+ mice (G), whereas neither feature was apparent in CCR5-/- mice (H). Total lymphocyte numbers in the CCR5+/+ BAL were increased over CCR5-/- mice at day 40 after conidia. However, this increase did not translate into conspicuous inflammatory differences when compared by photomicrograph with CCR5-/- mice (I, J). Original magnification was $200 \times$ for each photomicrograph. 
Fig. 6

Day 2 after Conidia

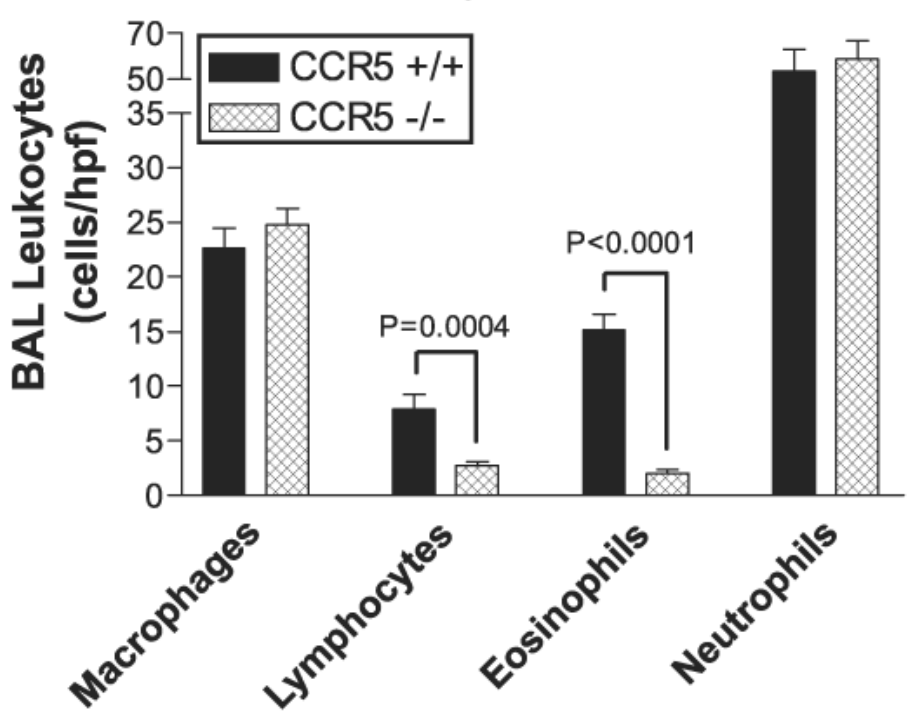

Day 21 after Conidia

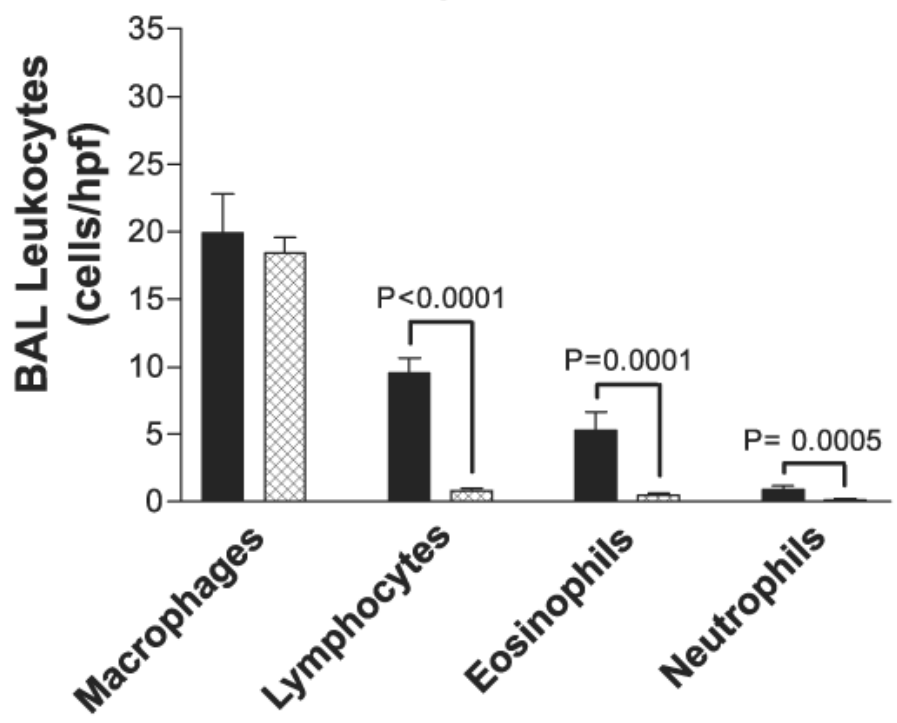

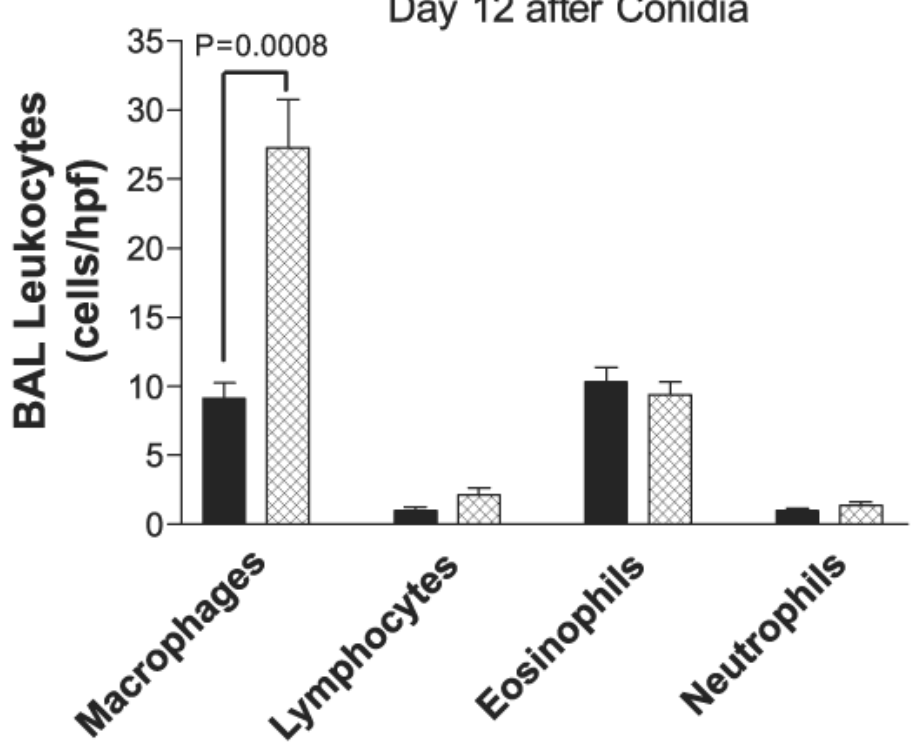

Day 40 after Conidia

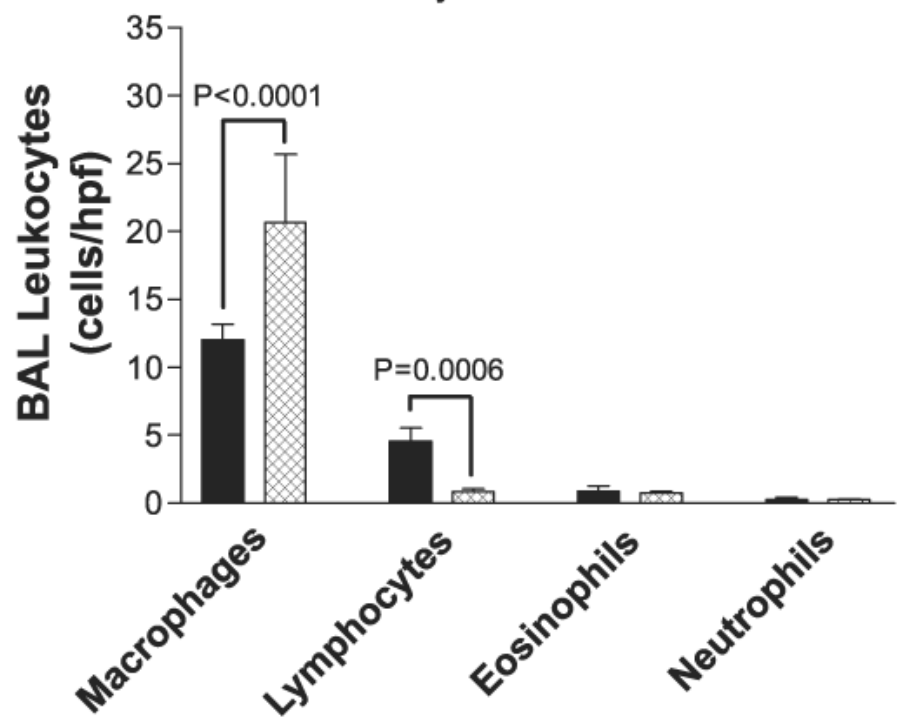

Figure 6. Leukocyte counts in bronchoalveolar lavage (BAL) samples from A. fumigatus-sensitized C-C chemokine receptor-5 (CCR5) wild-type (+/+) and CCR5 knockout (-/-) mice at days 2, 12, 21, and 40 after a live $A$. fumigatus conidia challenge. BAL cells were dispersed onto microscope slides by using a cytospin; and eosinophils, neutrophils, T lymphocytes, and macrophages were stained differentially with Wright-Giesma stain. A minimum of 1020 high-powered fields (hpf) was examined in each cytospin. Values are expressed as the mean number of each cell type per hpf \pm SE. 
Fig. 7

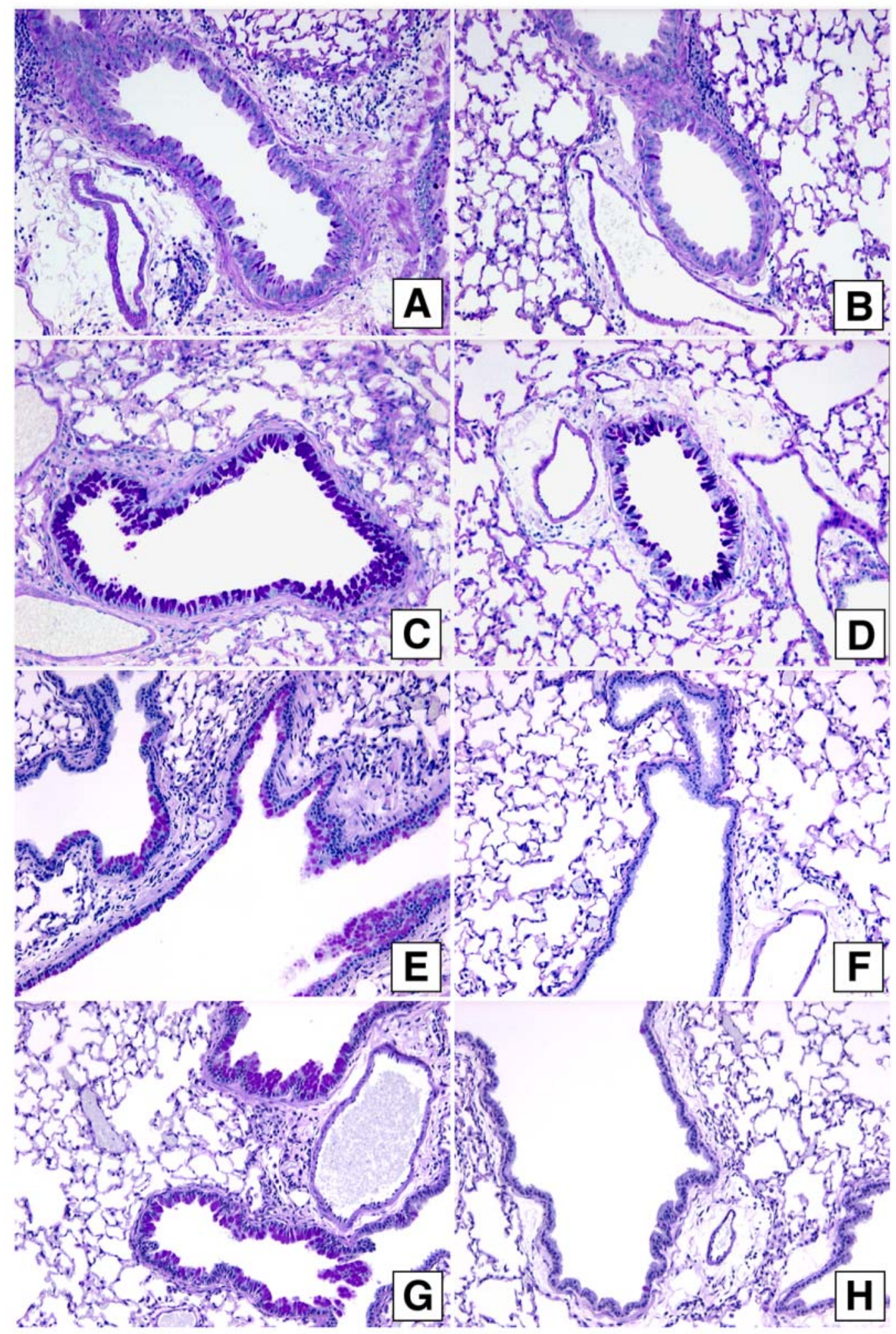

Figure 7. Representative photomicrographs of periodic acid Schiff (PAS)-stained whole lung sections from $A$. fumigatus-sensitized C-C chemokine receptor-5 (CCR5) wild-type (+/+) and CCR5 knockout (-/-) mice before, and at various times after, a live $\boldsymbol{A}$. fumigatus conidia challenge. At day 2 after conidia, goblet cells were apparent in the airways of CCR5+/+ mice (A), whereas few goblet cells were observed in the airways of CCR5-/- mice (B). Goblet cells were prominent in the airways of CCR5+/+ mice at days $12(\mathbf{C}), 21(\mathbf{E})$, and $40(\mathbf{G})$ after conidia. Goblet cells were present in the airways of CCR5-/- mice at day 12 after conidia (D), but not at days 21 (F) and 40 (H). Original magnification was $200 \times$ for each photomicrograph. 
Fig. 8

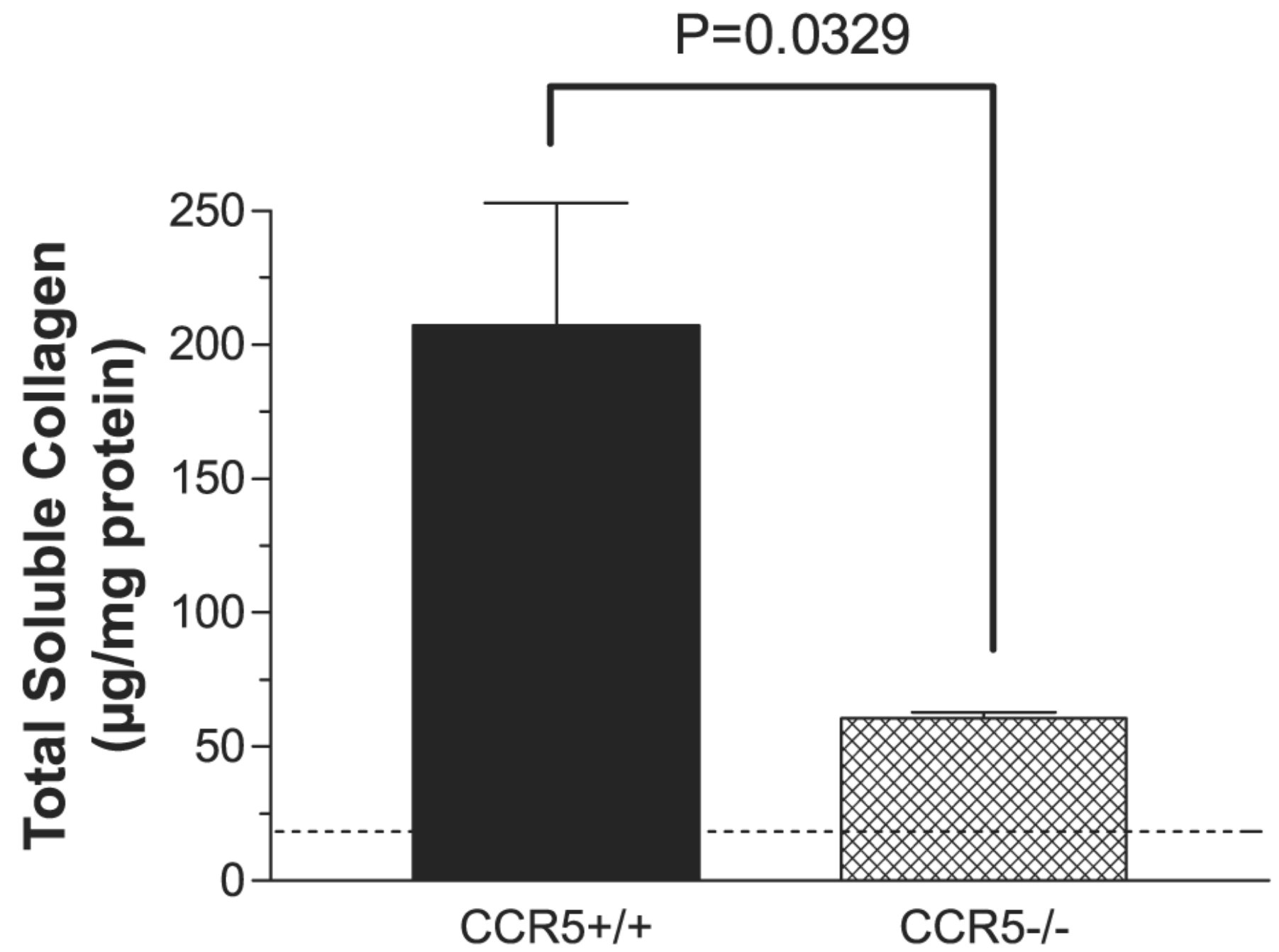

Figure 8. Total collagen levels in whole lung homogenates from $A$. fumigatus-sensitized C-C chemokine receptor-5 (CCR5) wild-type (+/+) and CCR5 knockout (-/-) mice at day 30 after a live A. fumigatus conidia challenge. Total collagen levels were measured as described in Materials and Methods. Values are expressed as mean \pm SE; $n=4-7 /$ group/time point. 
Fig. 9
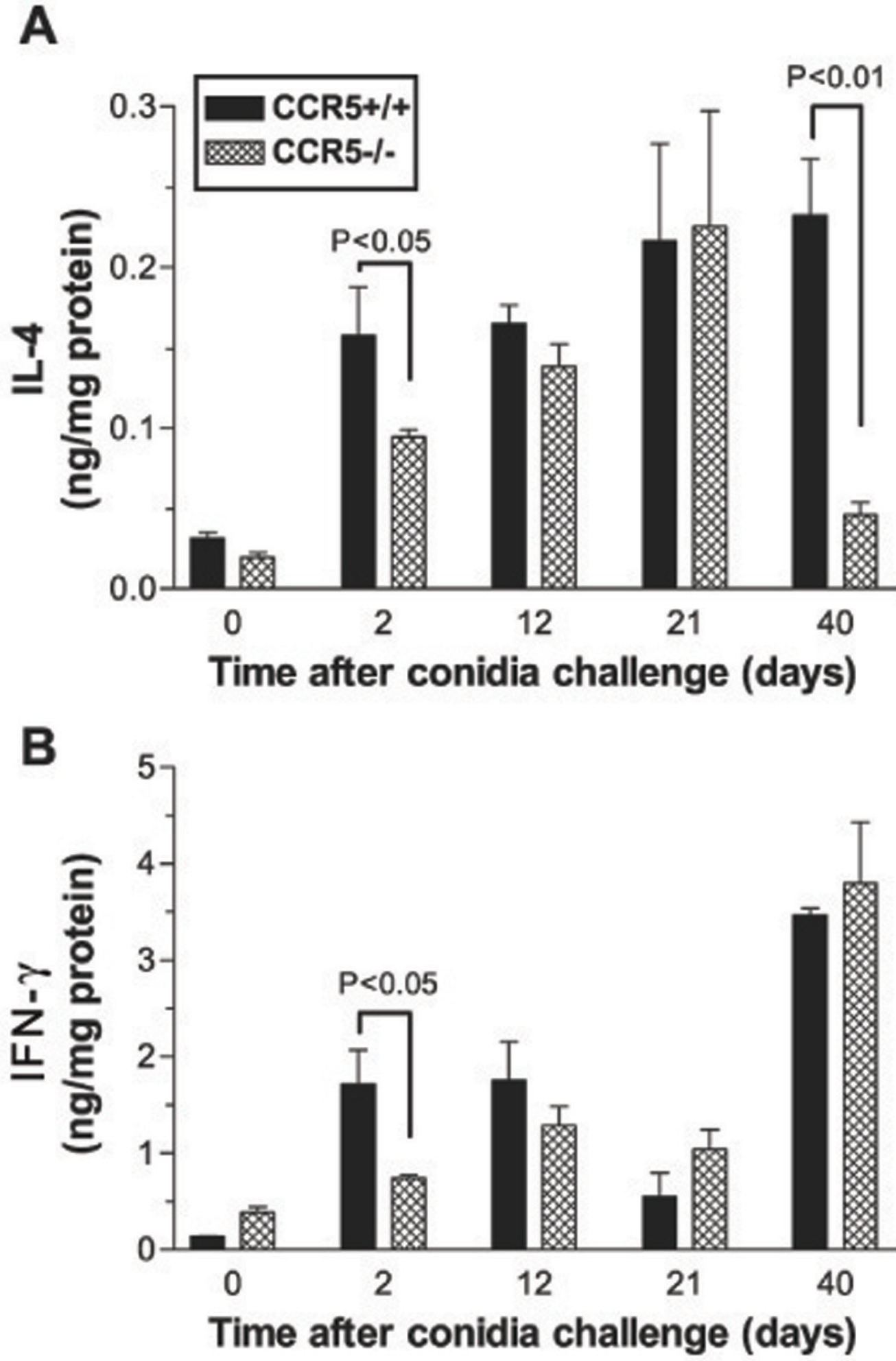

Figure 9. IL-4 (A) and IFN- $\gamma$ (B) levels in whole lung homogenates from $A$. fumigatus-sensitized sensitized C-C chemokine receptor-5 (CCR5) wild-type (+/+) and CCR5 knockout (-/-) mice before and at various times after $A$. fumigatus conidia challenge. Immunoreactive levels of IL-4 and IFN- $\gamma$ were measured by using a specific ELISA as described in Materials and Methods. Values are expressed as mean $\pm \mathrm{SE} ; n=4-7$ mice/group $t^{\prime}$ ime point. 
Fig. 10

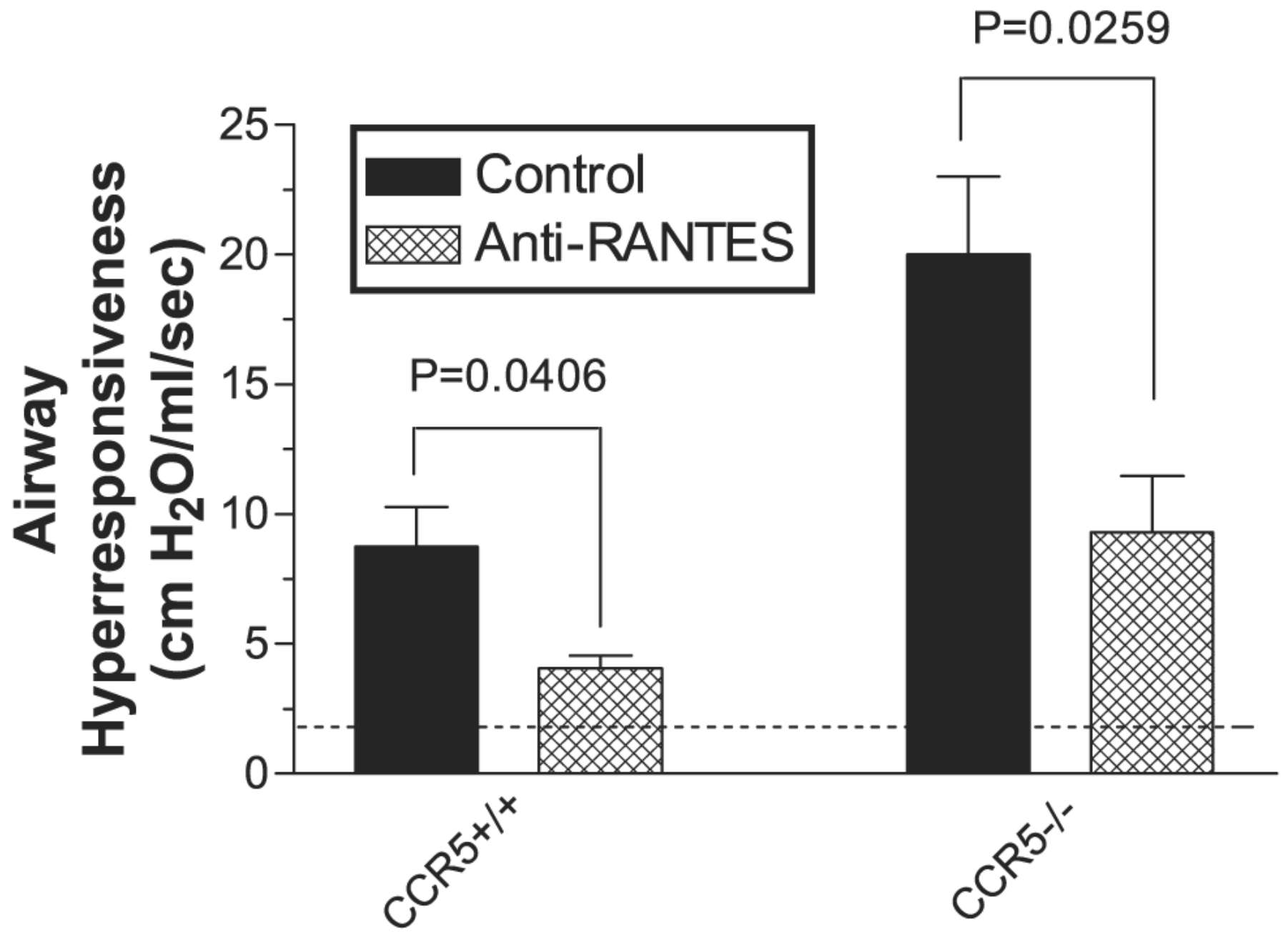

Figure 10. Airway hyperresponsiveness in A. fumigatus-sensitized C-C chemokine receptor-5 (CCR5) wild-type $(+/+)$ and CCR5 knockout (-/-) mice treated with normal goat serum (control) or anti-RANTES antibody after intrapulmonary challenge with live $\boldsymbol{A}$. fumigatus conidia. Peak increases in airway resistance or hyperresponsiveness (units $=\mathrm{cm} \mathrm{H}_{2} \mathrm{O} / \mathrm{ml} / \mathrm{s}$ ) were determined at each time point after the intravenous injection of methacholine. Values are expressed as mean \pm SE; $n=4-7 /$ group/time point. 
Fig. 11

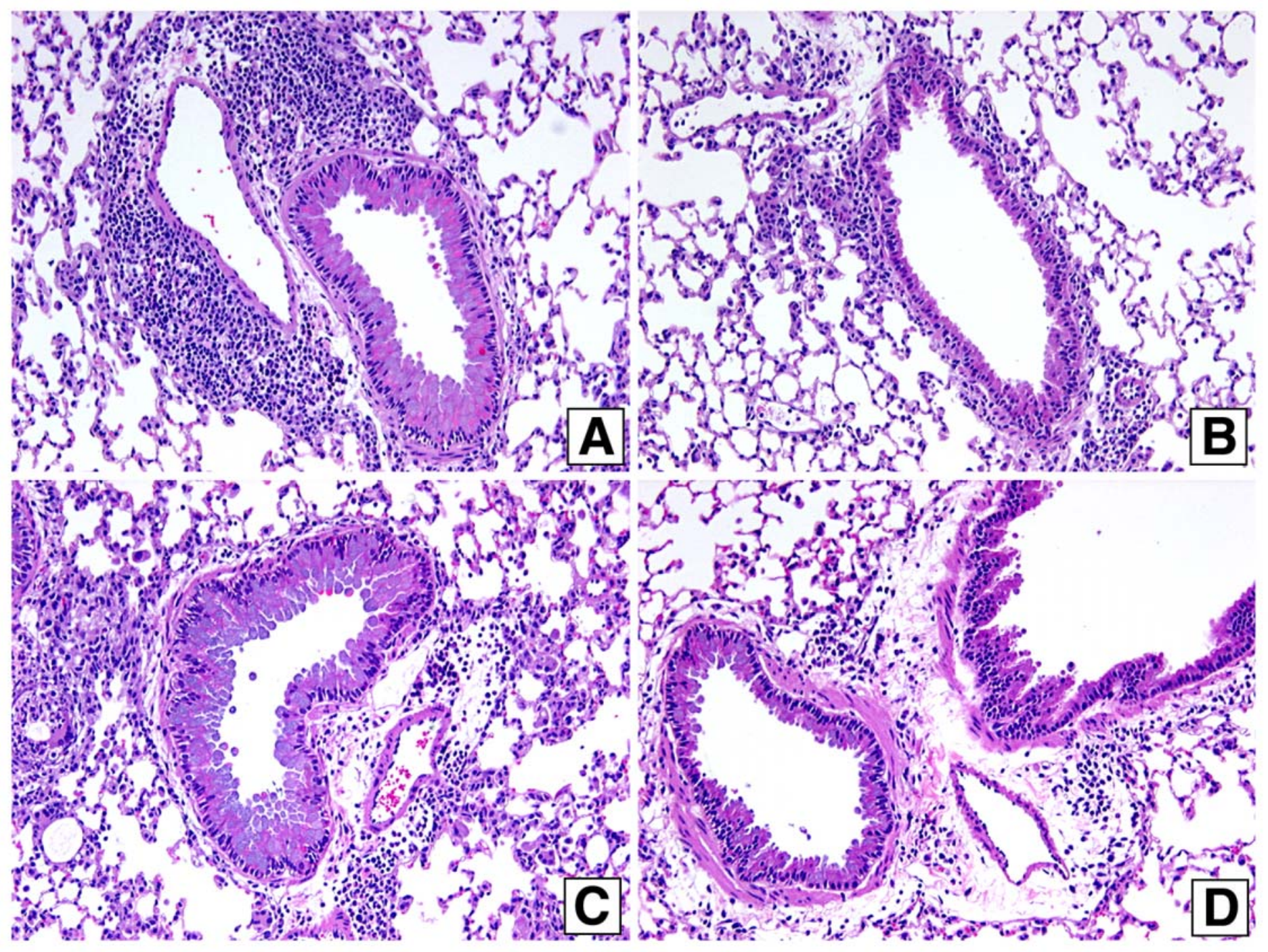

Figure 11. Representative photomicrographs of hematoxylin and eosin $(H \& E)$-stained whole lung sections from $A$. fumigatus-sensitized C-C chemokine receptor-5 (CCR5) wild-type (+/+) and CCR5 knockout (-/-) mice treated with intraperitoneal injections of normal goat serum or anti-RANTES antibody at day 12 after a live $A$. fumigatus conidia challenge. Inflammation is apparent around both the vasculature and airways of the CCR $5+/+$ mice treated with NGS (A), whereas inflammation was observed predominantly around the vessels only of CCR5-/- mice (B). Interstitial inflammation was apparent in CCR5+/+ mice treated with anti-RANTES (C), whereas CCR5-/- mice showed clear reduction of interstitial, perivascular, and peribronchial cell infiltrates (D). Original magnification was $200 \times$ for each photomicrograph. 
Fig. 12

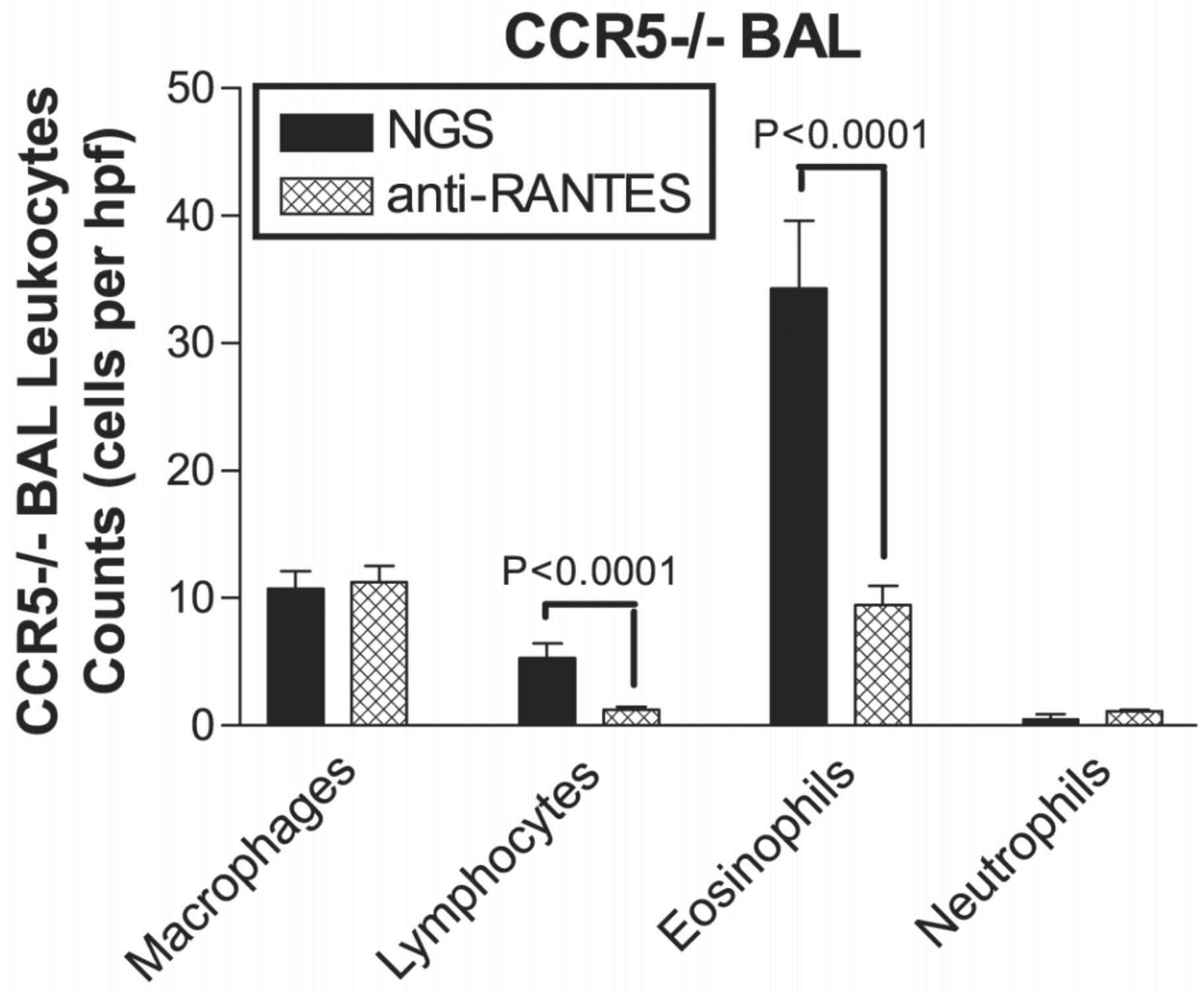

Figure 12. Leukocyte counts in bronchoalveolar lavage (BAL) samples at day 12 after a live $A$. fumigatus conidia challenge from sensitized C-C chemokine receptor-5 (CCR5) knockout (-/-) mice treated every $48 \mathrm{~h}$ from day 0-12 with anti-RANTES antibody. BAL cells were dispersed onto microscope slides by using a cytospin; eosinophils, neutrophils, T lymphocytes, and macrophages were stained differentially with Wright-Giesma stain. A minimum of 1020 high-powered fields (hpf) was examined in each cytospin. Values are expressed as the mean number of each cell type per hpf \pm SE. 